\title{
Transport and structural properties of osmotic membranes in high-salinity desalination using cascading osmotically mediated reverse osmosis
}

\author{
Xi Chen ${ }^{\mathrm{a}}$, Chanhee Boo ${ }^{\mathrm{a}}$, Ngai Yin Yip ${ }^{\mathrm{a}, \mathrm{b}, *}$ \\ ${ }^{a}$ Department of Earth and Environmental Engineering, Columbia University, New York, NY 10027-6623, United States \\ ${ }^{\mathrm{b}}$ Columbia Water Center, Columbia University, New York, NY 10027-6623, United States
}

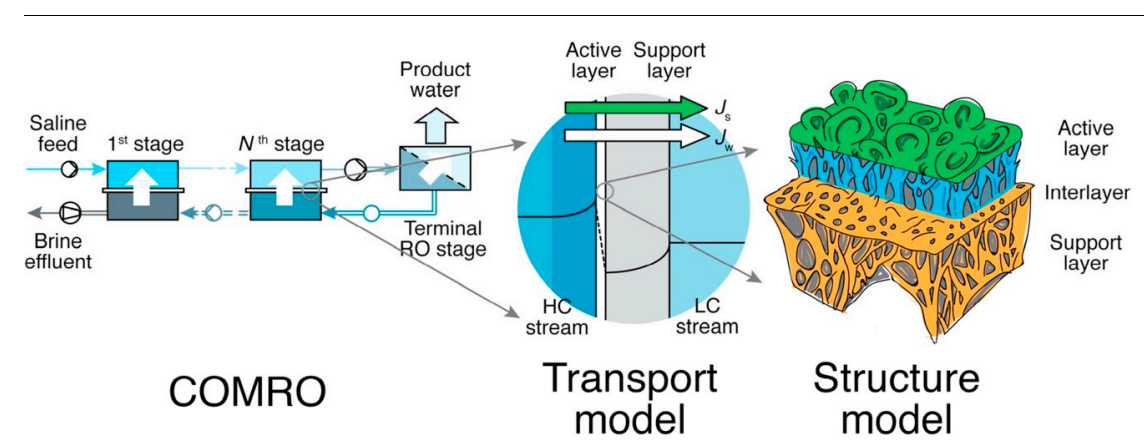

\section{A B S T R A C T}

Management of high-salinity brines is a global environmental challenge. Recently, we proposed a novel cascading osmotically mediated reverse osmosis (COMRO) technology for energy-efficient hypersaline desalination. In this study, a transport model is established for COMRO. We investigate the impacts of hydraulic pressure and salinity on transport and structural properties of thin-film composite osmotic membranes in COMRO. Our results show that transport properties are not affected by transitory pressure changes on the order of hours. But on longer timescales, on the order of days, the membrane undergoes compaction/relaxation in response to pressurization/depressurization, with water and salt permeabilities declining/recovering accordingly. Importantly, the water and salt permeabilities change in the same proportion. We found that this is due to morphological changes of the active-support interlayer altering the effective membrane area. The membrane structural parameter is demonstrated to be consistent at different salinities. As salinity increases, both water and salt permeabilities increase, but salt permeability rises substantially more. Lastly, the presented transport model is validated by good agreement between experimental and predicted water fluxes. This study advances the understanding of membrane transport and structural properties in the emerging COMRO technology, and provides insights into water and salt transport for other osmotic membrane processes.

\section{Introduction}

Treatment of high-salinity brines $(>\approx 70,000 \mathrm{ppm}$ total dissolved solids, TDS) has rapidly become an important environmental challenge globally [1,2]. A substantial amount of hypersaline brines is generated from the oil and gas industry (several million cubic meters per day in the U.S. alone) [3-5], minimum/zero-liquid discharge operations [6], inland desalination [7], landfill leachate [8], and flue gas desulfurization [9]. Prevailing desalination methods are all thermally-driven processes based on liquid-vapor phase change of water, which intrinsically requires intensive energy input $\left(\approx 630 \mathrm{kWh} / \mathrm{m}^{3}\right)[10,11]$.

Reverse osmosis (RO) is the most energy-efficient method for seawater and brackish water desalination [12-14], but the current state-ofthe-art of RO is unsuitable for desalination of high-salinity brines. As

\footnotetext{
* Corresponding author at: Department of Earth and Environmental Engineering, Columbia University, New York, NY 10027-6623, United States.

E-mail address: n.y.yip@columbia.edu (N.Y. Yip).
} 


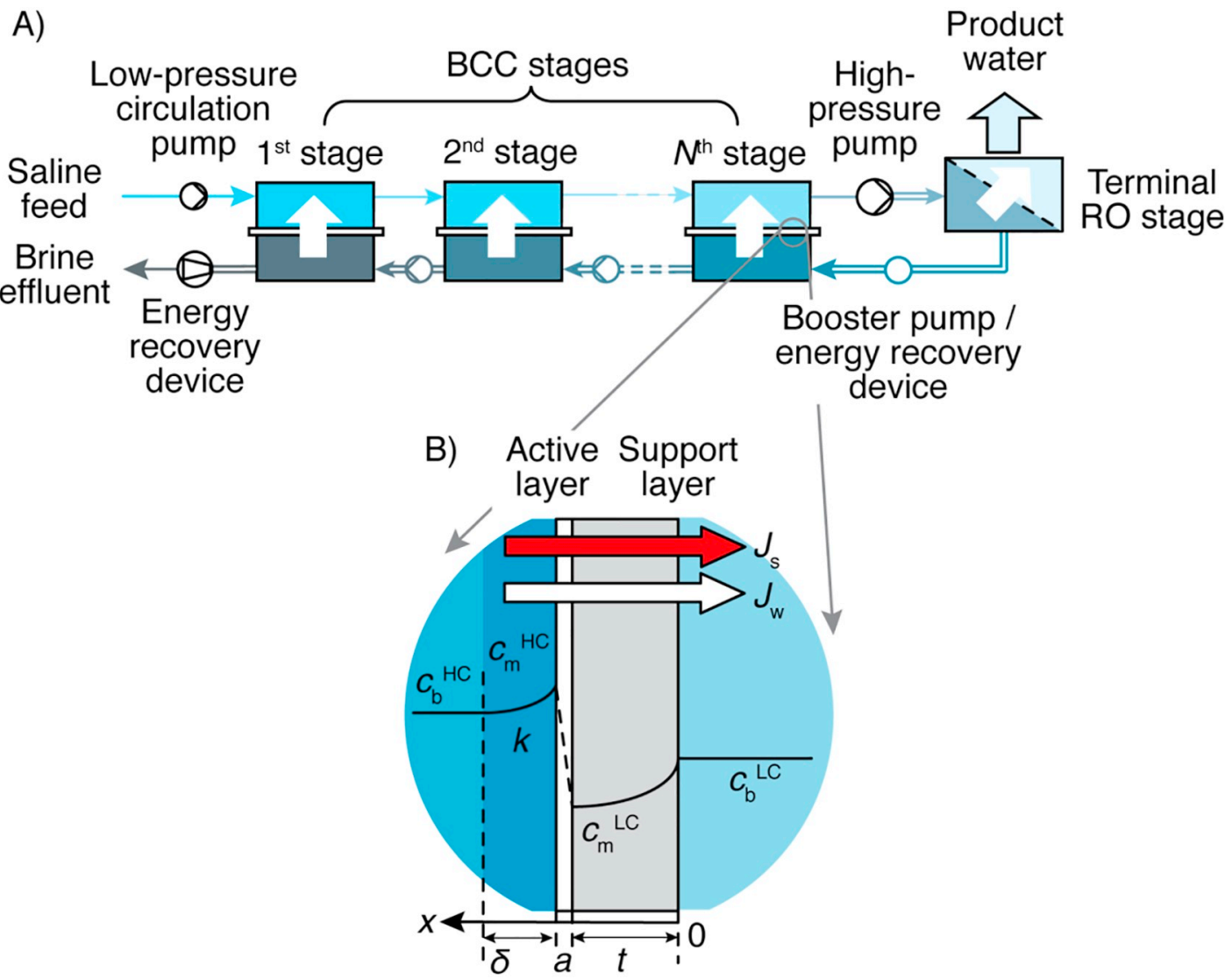

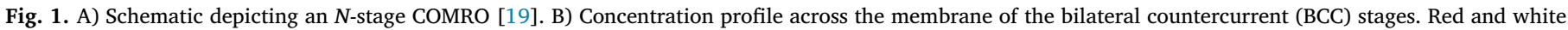
arrows denote directions of salt and water fluxes, respectively, and darker color intensity of the blue regions represents higher concentration.

the osmotic pressure scales with solute concentration, high-salinity RO desalination requires exceedingly high hydraulic pressure to overcome the transmembrane osmotic pressure difference. However, studies have reported severe deterioration of membrane performance during such high-pressure operations [15-17]. Although "high-pressure RO" has recently been proposed as an alternative to distillation-based methods for hypersaline brines [18], it is likely not a trivial challenge to design suitable high-strength membrane materials without compromising membrane transport properties. Additionally, implementation of mechanically robust membrane modules and system components to the high pressurizations will also likely require considerable capital cost. Even if high-pressure RO is realized, hypersaline desalination using conventional single-stage RO will have lower energy efficiencies, because the specific energy consumption increases proportionally with the higher pressures applied.

To overcome limitations of conventional RO, we proposed a novel "cascading osmotically mediated reverse osmosis" (COMRO) membrane technology for energy-efficient desalination of hypersaline brines [19]. Working principles of COMRO can be found elsewhere and are briefly explained here with Fig. 1A. COMRO utilizes the innovative design of bilateral countercurrent (BCC) reverse osmosis stages to lessen the osmotic pressure difference across the membrane, thus substantially depressing the hydraulic pressure needed and simultaneously achieve energy saving in high-salinity desalination [19]. Membranes in COMRO are challenged by atypical working environments, including high pressures and high salinities, under which transport and structural properties of the membrane may alter from those in conventional osmotically-driven processes. Understanding of fundamental water and salt transport properties in COMRO is necessary to advance the nascent technology and inform the design of customized membranes for enhanced performance.
This study aims to systematically investigate transport and structural properties of polyamide thin-film composite osmotic membranes in conditions representative of COMRO operation. A framework describing water and salt transport across the membrane in COMRO is first presented. Impacts of hydraulic pressure on membrane water and salt permeabilities are examined and related to morphological changes of the membrane active-support layer interface. The influence of bulksolution salinity on membrane structural parameter is assessed. Effects of high salinities on membrane water and salt permeabilities are also investigated, using a revised method for simultaneous determination of transport and structural parameters. Lastly, the transport models are validated by experimental data in bench-scale COMRO tests. Findings of this study shed light on the effects of hydraulic pressure and salinity on key membrane properties that govern transport in COMRO.

\section{Theory}

\subsection{Transport phenomena in COMRO}

In the bilateral countercurrent (BCC) stages of COMRO, the retentate stream (higher concentration) is pressurized to drive water permeation across the membrane, thus diluting the feed stream (lower concentration) [19]. The local water and salt transport across a thinfilm composite (TFC) membrane in a BCC stage are illustrated by the schematic in Fig. 1B, where the active layer is facing the high-concentration (HC) stream, while the support layer is in contact with the low-concentration (LC) stream. The hydraulic pressure is applied at the $\mathrm{HC}$ side, driving water and salt fluxes across the membrane in the same direction from the high- to low-concentration side.

A mass transfer boundary layer with thickness of $\delta$ is formed on the HC-stream side, at the solution-membrane active layer interface, with 
concentrative external concentration polarization (ECP) raising the bulk-phase solute concentration $c_{\mathrm{b}}{ }^{\mathrm{HC}}$ to $c_{\mathrm{m}}{ }^{\mathrm{HC}}$. On the LC-stream side, internal concentration polarization (ICP) decreases the solute concentration across the support layer from $c_{\mathrm{b}}{ }^{\mathrm{LC}}$ to $c_{\mathrm{m}}{ }^{\mathrm{LC}}$ at the activesupport layer interface. Accordingly, the concentration difference across the membrane interfaces is greater compared with that across the bulk phases, i.e., $c_{\mathrm{m}}{ }^{\mathrm{HC}}-c_{\mathrm{m}}{ }^{\mathrm{LC}}>c_{\mathrm{b}}{ }^{\mathrm{HC}}-c_{\mathrm{b}}{ }^{\mathrm{LC}}$, thus increasing the transmembrane osmotic pressure difference to overcome. Although there is likely to be ECP on the LC side, previous studies and also experimental results of this work found the effect to be relatively small $[20,21]$, and was therefore not explicitly considered in this analysis. Instead, ECP is effectively incorporated into mass transfer resistance of the unstirred support layer.

\subsection{Theoretical models of water and salt transport in COMRO}

In the HC boundary layer and porous support, the overall salt flux, $J_{s}$, is the sum of the diffusive component, driven by the salt concentration gradient, and the convective component, carried by the water flux, $J_{\mathrm{w}}[22-24]$ :

$J_{\mathrm{s}}=D_{\mathrm{eff}} \frac{d c(x)}{d x}+J_{\mathrm{w}} c(x)$

where the salt concentration $c$ is expressed as a function of the position $x$ (Fig. 1B) and $D_{\text {eff }}$ is the effective diffusion coefficient of the solute in a certain layer. The steady-state salt flux across the active layer is expressed as $J_{\mathrm{s}}=B\left(c_{\mathrm{m}}{ }^{\mathrm{HC}}-c_{\mathrm{m}}{ }^{\mathrm{LC}}\right)$ [24], where $c_{\mathrm{m}}{ }^{\mathrm{LC}}$ and $c_{\mathrm{m}}{ }^{\mathrm{HC}}$ are the solute concentrations at the active layer interface on the LC and HC sides, respectively, and $B$ is the salt permeability of the membrane. At steady state, salt flux across the HC boundary layer, porous support, and membrane active layer are equivalent:

$\left[D_{\mathrm{eff}}^{\mathrm{ECP}} \frac{d c(x)}{d x}+J_{\mathrm{w}} c(x)\right]_{\mathrm{ECP}}=\left[D_{\mathrm{eff}}^{\mathrm{ICP}} \frac{d c(x)}{d x}+J_{\mathrm{w}} c(x)\right]_{\mathrm{ICP}}=B\left(c_{\mathrm{m}}^{\mathrm{HC}}-c_{\mathrm{m}}^{\mathrm{LC}}\right)$

Corresponding boundary conditions of the support are $c=c_{\mathrm{b}}{ }^{\mathrm{LC}}$ at $x=0$ and $c=c_{\mathrm{m}}{ }^{\mathrm{LC}}$ at $x=t$; while $c=c_{\mathrm{m}}{ }^{\mathrm{HC}}$ at $x=t+a$ and $c=c_{\mathrm{b}}{ }^{\mathrm{HC}}$ at $x=t+a+\delta$ for the HC boundary layer, where $t, a$, and $\delta$ are thickness of the support layer, active layer, and the HC boundary layer, respectively (Fig. 1B). Integrating Eq. (2) across the HC-stream boundary layer and the support layer yields $c_{\mathrm{m}}{ }^{\mathrm{HC}}$ and $c_{\mathrm{m}}{ }^{\mathrm{LC}}$, respectively. $D_{\text {eff }}$ of the HC boundary layer is identical to the bulk-phase diffusivity, $D$, while the effective diffusivity of the porous support can be derived from $D$ by accounting for the porosity $(\varepsilon)$ and tortuosity $(\tau)$ of the support layer: $D_{\text {eff }}=D \varepsilon / \tau$. Defining membrane structural parameter, $S \equiv t \tau / \varepsilon, D_{\text {eff }}$ can be substituted by $D t / S$, and complete derivations of $c_{\mathrm{m}}^{\mathrm{LC}}$ and $c_{\mathrm{m}}^{\mathrm{HC}}$ are:

$c_{\mathrm{m}}^{\mathrm{LC}}=\frac{\frac{B}{J_{\mathrm{W}}}\left[1-\exp \left(-\frac{J_{\mathrm{W}} S}{D}\right)\right] \exp \left(\frac{J_{\mathrm{W}}}{k}\right) c_{\mathrm{b}}^{\mathrm{HC}}+\left\{1+\frac{B}{J_{\mathrm{W}}}\left[\exp \left(\frac{J_{\mathrm{W}}}{k}\right)-1\right]\right\} \exp \left(-\frac{J_{\mathrm{W}} S}{D}\right) c_{\mathrm{b}}^{\mathrm{LC}}}{1+\frac{B}{J_{\mathrm{W}}}\left[\exp \left(\frac{J_{\mathrm{W}}}{k}\right)-\exp \left(-\frac{J_{\mathrm{W}} S}{D}\right)\right]}$

$c_{\mathrm{m}}^{\mathrm{HC}}=\frac{\left\{1+\frac{B}{J_{\mathrm{W}}}\left[1-\exp \left(-\frac{J_{\mathrm{W}} S}{D}\right)\right]\right\} \exp \left(\frac{J_{\mathrm{W}}}{k}\right) c_{\mathrm{b}}^{\mathrm{HC}}+\frac{B}{J_{\mathrm{W}}}\left[\exp \left(\frac{J_{\mathrm{W}}}{k}\right)-1\right] \exp \left(-\frac{J_{\mathrm{W}} S}{D}\right) c_{\mathrm{b}}^{\mathrm{LC}}}{1+\frac{B}{J_{\mathrm{W}}}\left[\exp \left(\frac{J_{\mathrm{W}}}{k}\right)-\exp \left(-\frac{J_{\mathrm{W}} S}{D}\right)\right]}$

where $k=D / \delta$ is the mass transfer coefficient of the HC-stream boundary layer.

Here we note that because of the atypically high concentrations in COMRO operations, the osmotic pressure is not linearly proportional to the concentration [25]. Hence, the widely adopted assumption that $\Delta \pi_{\mathrm{m}}$ $\propto \Delta c_{\mathrm{m}}$ may introduce significant inaccuracies [21,26] and is, thus, not suitable. Therefore, in this analysis, membrane interfacial osmotic pressures are determined using more accurate nonlinear functions of concentration, $\pi(c)$. With Eqs. (3) and (4), water flux can be further calculated as $J_{\mathrm{w}}=A\left\{\Delta P-\left[\pi\left(c_{\mathrm{m}}{ }^{\mathrm{HC}}\right)-\pi\left(c_{\mathrm{m}}{ }^{\mathrm{LC}}\right)\right]\right\}$, where $A$ is the membrane water permeability, and $\Delta P$ is the applied transmembrane hydralic pressure difference.

\section{Materials and methods}

\subsection{Osmotic membranes and chemicals}

Flat sheets of commercial thin-film composite (TFC) osmotic membranes from Toray Chemical (FO4040, Seoul, South Korea) were used for all experiments. The TFC osmotic membrane comprises a polyamide active layer on top of a highly porous polysulfone support with nonwoven polyester fibers embedded for mechanical robustness [27]. Membranes were prepared by soaking in $25 \mathrm{v} / \mathrm{v} \%$ isopropanol to remove any protective coatings, followed by washing with deionized (DI) water, and then kept in DI water at $4{ }^{\circ} \mathrm{C}$. Unless otherwise specified, all the experiments were carried out in duplicates using fresh membrane coupons. The saline HC and LC streams were simulated by dissolving ACS grade sodium chloride ( $\mathrm{NaCl}$, Fisher Scientific, Hanover Park, IL) or magnesium sulfate heptahydrate $\left(\mathrm{MgSO}_{4} \cdot 6 \mathrm{H}_{2} \mathrm{O}\right.$, Alfa Aesar, Haverhill, MA) in DI water.

\subsection{Determination of membrane transport properties under different hydraulic pressures}

Water and salt permeabilities of the TFC osmotic membrane at different hydraulic pressures were characterized in a custom-built COMRO unit that can also be operated in RO and FO mode. Channel depths of the LC- and HC-stream sides are 0.5 and $3.0 \mathrm{~mm}$, respectively, and identical length and width of 107 and $36 \mathrm{~mm}$ are employed for the channels on both sides. $A$ and $B$ values were evaluated in RO mode by pressurizing the feed solution on HC side and employing the LC-stream as the permeate solution. Feed-stream hydraulic pressures were generated by a Hydra-Cell diaphragm pump (Wanner Engineering Inc., Minneapolis, MN) and a gear pump (Langer Instruments, Tucson, AZ) was used to circulate the permeate stream. The hydraulic pressure and flowrate of the feed (HC) stream were adjusted by a back-pressure regulator and a flow-control needle valve. Effective membrane area of $19.0 \mathrm{~cm}^{2}(2.5 \times 7.6 \mathrm{~cm})$ was exposed to both streams, and a customized two-layer woven tricot spacer was applied in the permeate (LC) channel to support the membrane and enhance hydrodynamics. The direction of water and salt fluxes, concentration profile across the membrane, and application of hydraulic pressure are depicted in Fig. 2A, B, and C for RO, FO, and COMRO operation, respectively.

\subsubsection{Determination of membrane water permeability under different hydraulic pressures}

To determine membrane water permeability, DI water was used as the feed and permeate streams in co-current flow, at flowrates of 1 and $0.2 \mathrm{~L} / \mathrm{min}$, respectively. Steady-state water flux, $J_{\mathrm{w}}{ }^{\mathrm{DI}}$, under hydraulic pressure, $\Delta P$, after operating over $12 \mathrm{~h}$ was obtained by monitoring the rate of change in weight of the permeate tank. The corresponding water permeability, $A$, was determined as $A=J_{\mathrm{w}}^{\mathrm{DI}} / \Delta P$.

Different $\Delta P$ were applied to systematically evaluate membrane water permeability $(A)$ under three different scenarios. First, $A$ under "compaction" scenario was investigated by determining the steadystate membrane water permeability after $>12 \mathrm{~h}$ of hydraulic pressurization at 6.9 bar (100 psi). $\Delta P$ is then raised to 13.8 bar (200 psi) and compacted over $12 \mathrm{~h}$ again before characterizing $A$. The characterization is then repeated for 27.6 bar (400 psi). For "short-term persistence" scenario, the membrane was first compacted for $12 \mathrm{~h}$ under $27.6 \mathrm{bar}$ and $A$ is determined. Then $\Delta P$ was decreased to 13.8 bar and the steadystate $A$ was immediately measured within 2 h (i.e., no $12 \mathrm{~h}$ stabilization). Membrane water permeability was characterized with the same protocol again after lowering $\Delta P$ to 6.9 bar. Lastly for "relaxation and re-compaction" scenario, membranes were first compacted under $27.6 \mathrm{bar}$ for over $12 \mathrm{~h}$ and steady-state $A$ was recorded. The membranes 

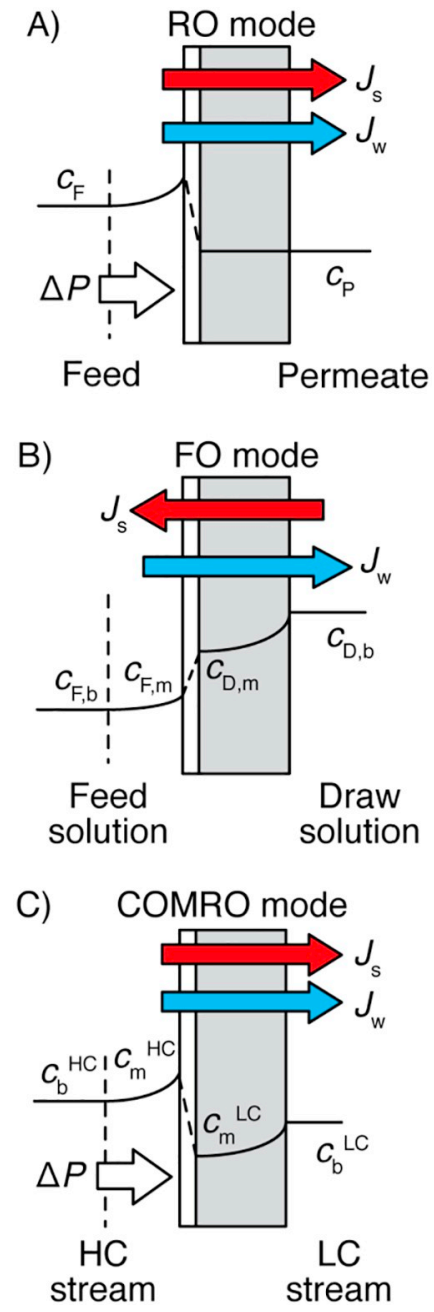

Fig. 2. Schematics depicting water and salt transport, and concentration profile across the membrane in A) RO, B) FO, and C) COMRO modes for membrane characterization experiments. Red, blue, and white arrows denote directions of salt flux $\left(J_{\mathrm{s}}\right)$, water flux $\left(J_{\mathrm{w}}\right)$, and applied hydraulic pressure $(\Delta P)$, respectively. The orientation of the membrane is kept the same in all tests, i.e., left and right streams in all modes are in the HC-stream and LC-stream channels of the membrane cell, respectively. A customized two-layer woven tricot spacer was used in the LC channel.

were then kept unpressurized for 20 days to allow for relaxation of the polymeric material. Values of $A$ were measured for $30 \mathrm{~min}$ in quick succession under hydraulic pressures of $6.9 \mathrm{bar} \rightarrow 13.8 \mathrm{bar} \rightarrow 27.6 \mathrm{bar}$ (i.e., before steady state is reached). Operating details of the three scenarios are summarized in Table 1.

\subsubsection{Determination of membrane salt permeability under different hydraulic pressures}

Salt permeabilities under different hydraulic pressures were investigated under the "compaction" and "short-term persistence" scenarios described earlier in the evaluation of $A$. In the "compaction" scenario, membranes were compacted using DI water chronologically under $\Delta P$ of 3.4 bar $\rightarrow 6.9$ bar $\rightarrow 13.8$ bar $\rightarrow 27.6$ bar (50, 100, 200, and 400 psi, respectively). For each pressure after the DI water flux stabilized, i.e., $>12 \mathrm{~h}$, the feed stream was replaced with $25 \mathrm{mM} \mathrm{NaCl}$ and the steady-state salt rejections were characterized. The feed side was then flushed and replaced with DI water before characterization at the next $\Delta P$. Membranes in the "short-term persistence" scenario were first compacted by DI water under 27.6 bar ( 400 psi) over $12 \mathrm{~h}$, and the feed stream was then substituted with $25 \mathrm{mM} \mathrm{NaCl}$. The hydraulic pressure is lowered stepwise from $27.6 \mathrm{bar} \rightarrow 20.7 \mathrm{bar} \rightarrow 13.8 \mathrm{bar} \rightarrow$ 6.9 bar (with $>12 \mathrm{~h}$ stabilization each) and the stabilized salt rejections at each $\Delta P$ were determined. Details of operating scenarios are summarized in Table 1.

$\mathrm{NaCl}$ concentration of the permeate tank was continuously tracked by a calibrated conductivity meter (ThermoFisher Scientific, Waltham, MA). Observed $\mathrm{NaCl}$ rejection, $R$, was determined from the difference in bulk-phase feed $\left(c_{\mathrm{F}}\right)$ and permeate $\left(c_{\mathrm{P}}\right)$ concentrations, $R=1-c_{\mathrm{P}} / c_{\mathrm{F}}$. The membrane salt permeability, $B$, was calculated using [24]:

$B=J_{\mathrm{w}}\left(\frac{1-R}{R}\right) \exp \left(-\frac{J_{\mathrm{w}}}{k}\right)$

where $k$ is the feed-stream mass transfer coefficient, calculated using film-theory model [28].

\subsection{Membrane characterization by scanning electronic microscopy}

Cross-section of the TFC osmotic membranes before and after hydraulic compaction was characterized using scanning electron microscopy (SEM, Zeiss Sigma VP, Oberkochen, Germany). Membranes were compacted in the membrane cell using DI water as the feed stream at hydraulic pressure of 27.6 bar for $>12 \mathrm{~h}$, with stabilized water flux indicating steady state is attained. The compacted membrane coupon was removed from the cell and immediately dehydrated by soaking into pure ethanol several times. The sample was then further dried in a vacuum oven (Across International, Livingston, NJ) for 15 min to remove residual ethanol. Both the pristine membrane (i.e., without compaction) and the membrane after hydraulic compaction were frozen in liquid nitrogen and then fractured, aided by light scoring with a razor blade. All samples were sputter-coated with a 20-nm gold layer (108 auto sputter, Cressington, UK) before imaging. SEM imaging was

Table 1

Summary of operating conditions to determine water and salt permeability under different hydraulic pressures using three pressurization scenarios.

\begin{tabular}{|c|c|c|c|c|c|c|c|c|c|}
\hline \multirow[t]{2}{*}{ Scenario } & \multirow{2}{*}{$\begin{array}{l}\text { Tests of } \\
\text { Stage }\end{array}$} & \multicolumn{4}{|c|}{ Water permeability } & \multicolumn{4}{|c|}{ Salt permeability } \\
\hline & & 1 & 2 & 3 & 4 & 1 & 2 & 3 & 4 \\
\hline \multirow[t]{4}{*}{ Compaction } & $\Delta P$ (bar) & 6.9 & 13.8 & 27.6 & N/A & 3.4 & 6.9 & 13.8 & 27.6 \\
\hline & Relaxation (d) & No & No & No & N/A & No & No & No & No \\
\hline & Duration (min) & $>720$ & $>720$ & $>720$ & N/A & $>720$ & $>720$ & $>720$ & $>720$ \\
\hline & Steady state & Yes & Yes & Yes & N/A & Yes & Yes & Yes & Yes \\
\hline \multirow[t]{4}{*}{ Short-term persistence } & $\Delta P$ (bar) & 27.6 & 13.8 & 6.9 & N/A & 27.6 & 20.7 & 13.8 & 6.9 \\
\hline & Relaxation (d) & No & No & No & N/A & No & No & No & No \\
\hline & Duration (min) & $>720$ & 120 & 120 & N/A & $>720$ & $>720$ & $>720$ & $>720$ \\
\hline & Steady state & Yes & Yes & Yes & N/A & Yes & Yes & Yes & Yes \\
\hline \multirow[t]{4}{*}{ Relaxation and re-compaction } & $\Delta P($ bar $)$ & 27.6 & 6.9 & 13.8 & 27.6 & & & & \\
\hline & Relaxation (d) & No & 20 & No & No & & & & \\
\hline & Duration (min) & $>720$ & 30 & 30 & 30 & & & & \\
\hline & Steady state & No & No & No & No & & & & \\
\hline
\end{tabular}


Table 2

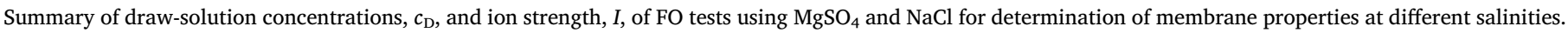

\begin{tabular}{|c|c|c|c|c|c|c|c|c|c|}
\hline \multirow{2}{*}{$\begin{array}{l}\text { Salinity } \\
I(\mathrm{M})\end{array}$} & \multicolumn{3}{|c|}{ Medium (MD) } & \multicolumn{3}{|c|}{ High (HI) } & \multicolumn{3}{|c|}{ Ultrahigh (UH) } \\
\hline & 0.3 & 0.6 & 0.9 & 0.9 & 1.4 & 1.9 & 1.9 & 2.9 & 3.9 \\
\hline$c_{\mathrm{D}, \mathrm{b}}{ }^{\mathrm{MgSO}_{4}}(\mathrm{M})$ & 0.075 & 0.15 & 0.225 & 0.225 & 0.35 & 0.475 & 0.475 & 0.725 & 0.975 \\
\hline$c_{\mathrm{D}, \mathrm{b}}{ }^{\mathrm{NaCl}}(\mathrm{M})$ & 0.3 & 0.6 & 0.9 & 0.9 & 1.4 & 1.9 & 1.9 & 2.9 & 3.9 \\
\hline
\end{tabular}

completed within $45 \mathrm{~min}$ after compaction to minimize potential recovery of membrane cross-sectional morphology.

\subsection{Determination of membrane parameters as a function of salinity}

\subsubsection{Characterization of membrane structural parameter across a range of} salinities

Structural parameter, $S$, of the TFC osmotic membrane is described by the thickness $(t)$, tortuosity $(\tau)$, and porosity $(\varepsilon)$ of the support layer as $S=t \tau / \varepsilon$ [29]. Three individual membrane coupons were soaked into $\mathrm{NaCl}$ solution of salinities ranging from 0 to $5 \mathrm{M}$ (292,500 ppm TDS) and equilibrated for $1 \mathrm{~h}$. Change in $S$ value at different salinities was determined from changes in $t, \tau$, and $\varepsilon$. Membrane thickness, $\approx t$, is measured by a digital micrometer. Membrane porosity, $\varepsilon$, is determined using a gravimetric method. Because density of the membrane matrix cannot be directly determined, here we utilize specific pore volume, $v_{\mathrm{p}}$, as a proxy for $\varepsilon$, where $v_{\mathrm{p}}$ is the ratio of pore volume to mass of the dry integral membrane:

$v_{\mathrm{p}}=\frac{m_{\mathrm{w}}-m_{\mathrm{d}}}{m_{\mathrm{d}} \rho_{\mathrm{NaCl}}}$

where $m_{\mathrm{w}}$ and $m_{\mathrm{d}}$ are mass of the wetted and dry membranes, respectively, and $\rho_{\mathrm{NaCl}}$ is the density of the $\mathrm{NaCl}$ solution. Therefore, porosity and specific pore volume are related by $\varepsilon=v_{\mathrm{p}} / \rho_{\mathrm{NaCl}}$. Pore tortuosity $(\tau)$ can be determined from the porosity using $\tau=\varepsilon^{-0.5}$ [30-32], and thus $\tau \propto v_{\mathrm{p}}{ }^{-0.5}$.

Here we define $\bar{\lambda}_{\mathrm{t}}, \bar{\lambda}_{\varepsilon}$ and $\bar{\lambda}_{\tau}$ as the normalized $t, \varepsilon$, and $\tau$ at different salinities, respectively. Specifically, $\bar{\lambda}_{\mathrm{t}} \equiv t / t_{0}, \bar{\lambda}_{\varepsilon}=\bar{\lambda}_{\mathrm{v}} \equiv v_{\mathrm{p}} / v_{\mathrm{p}, 0}$, and $\bar{\lambda}_{\tau}=\bar{\lambda}_{\mathrm{v}}{ }^{-0.5}$, where the subscripts " 0 " denote the parameters of the membrane in DI water (i.e., zero salinity). Therefore, the normalized change in $S$ can be expressed as $\bar{\lambda}_{\mathrm{S}}=\bar{\lambda}_{\mathrm{t}} \bar{\lambda}_{\tau} / \bar{\lambda}_{\varepsilon}=\bar{\lambda}_{\mathrm{t}} / \bar{\lambda}_{\mathrm{V}}{ }^{1.5}$, and the percentage change in the structural parameter is $\Delta \bar{S}=\bar{\lambda}_{\mathrm{S}}-1$.

\subsubsection{Determination of membrane water permeability at different salinities}

Water permeabilities of the TFC osmotic membrane at different salinities are simultaneously determined with the structural parameter using a revised method based on the forward osmosis (FO) model [21]. The FO experiments were conducted by placing DI water feed solution in contact with the active layer and $\mathrm{MgSO}_{4}$ draw solution in contact with the support layer (Fig. 2B). The double-layer woven tricot spacer was applied in the draw-solution channel to mechanically support the membrane and enhance hydrodynamics. In FO, water permeates from the feed solution to the draw solution and the reverse salt flux, $J_{\mathrm{s}}$, is in the opposite direction, from the draw solution to the feed solution.

The TFC osmotic membrane exhibits practically complete rejection of $\mathrm{MgSO}_{4}$ [24,33], hence salt permeability, $B$, for $\mathrm{MgSO}_{4}$ draw solution is assumed to be zero and $J_{\mathrm{s}} \approx 0$. Substituting $c_{\mathrm{b}}{ }^{\mathrm{HC}}$ and $c_{\mathrm{b}}{ }^{\mathrm{LC}}$ with $c_{\mathrm{F}, \mathrm{b}}$ and $c_{\mathrm{D}}$, b, respectively, reduces Eqs. (3) and (4) to $c_{\mathrm{D}, \mathrm{m}}=\exp \left(-J_{\mathrm{w}} S\right.$ / $\left.D_{\mathrm{MgSO}_{4}}\right) c_{\mathrm{D}}, \mathrm{b}$ and $c_{\mathrm{F}, \mathrm{m}}=\exp \left(J_{\mathrm{w}} / k\right) c_{\mathrm{F}}$, b, the draw- and feed-solution concentrations at the membrane interfaces $\left(D_{\mathrm{MgSO}_{4}}\right.$ is the diffusion coefficient of $\mathrm{MgSO}_{4}$, and $c_{\mathrm{D}, \mathrm{b}}$ and $\mathrm{c}_{\mathrm{F}, \mathrm{b}}$ are bulk-phase concentrations of the draw and feed solutions, respectively). Once $c_{\mathrm{D}, \mathrm{m}}$ and $\mathrm{c}_{\mathrm{F}, \mathrm{m}}$ are determined, water flux can be calculated using $J_{\mathrm{w}}=A$ $\left[\pi\left(c_{\mathrm{D}, \mathrm{m}}\right)-\pi\left(c_{\mathrm{F}, \mathrm{m}}\right)\right]$ by accounting for the nonlinear $\Delta c_{\mathrm{m}}-\Delta \pi_{\mathrm{m}}$ relation, as mentioned earlier in Section 2.2. The draw-solution osmotic pressure as a function of concentration is determined from the polynomial equation: $\pi(c)=\alpha_{1} c^{3}+\alpha_{2} c^{2}+\alpha_{3} c$ [34], with the virial coefficients $\alpha_{1}$, $\alpha_{2}$, and $\alpha_{3}$ obtained by fitting the polynomial regression to osmotic pressure data across the range of $\mathrm{MgSO}_{4}$ solution concentrations obtained from OLI Stream Analyzer. We note that actual diffusivity of $\mathrm{MgSO}_{4}$ varies in the investigated salinity range but is within $8 \%$. Using the extreme end values of $D_{\mathrm{MgSO}_{4}}$ did not yield significant differences for the membrane water permeabilities and is, thus, considered to be constant at $0.584 \times 10^{-9} \mathrm{~m}^{2} \mathrm{~s}^{-1}$ [35].

FO tests were carried out using different draw-solution concentrations, representing medium (MD), high (HI), and ultrahigh (UH) salinities. For each salinity range, FO water fluxes, $J_{\mathrm{w}}{ }^{\mathrm{EXP}}$, were measured at three different draw-solution concentrations. Details of the concentration and the corresponding ionic strength of draw solutions employed for the FO experiments are summarized in Table 2. Two parameters, $A$ and $S$, can be simultaneously determined for each salinity range by fitting the experimental water fluxes, $J_{\mathrm{w}}{ }^{\mathrm{EXP}}$, to the calculated water fluxes, $J_{\mathrm{w}}{ }^{\mathrm{CAL}}$, using Eqs. (3) and (4) and minimizing the residual sum of normalized squares, $R s_{\mathrm{w}}$ :

$R s_{\mathrm{w}}=\sum_{i=1}^{n}\left(\frac{J_{\mathrm{w}, i}^{\mathrm{EX}}-J_{\mathrm{w}, i}^{\mathrm{CAL}}}{\bar{J}_{\mathrm{w}}^{\mathrm{EXP}}}\right)^{2}$

where $\bar{J}_{\mathrm{W}}^{\mathrm{EXP}}$ is the average of the experimental water flux, $i$ is the order of the individual test in a certain salinity range, and $n$ is the total number of the tests in a salinity range $(=3)$. The fitting process was realized using a nonlinear least-square algorithm for Python, implemented by LMFIT [36].

\subsubsection{Evaluation of membrane salt permeability as a function of salinity}

Membrane salt permeabilities at different salinities were characterized by a method similar to that described in Section 3.4.2, but using $\mathrm{NaCl}$ draw solutions with concentration up to $3.9 \mathrm{M}$ to generate the same ionic strength as the $\mathrm{MgSO}_{4}$ draw solution. By substituting $c_{\mathrm{b}}{ }^{\mathrm{HC}}$ and $c_{\mathrm{b}}{ }^{\mathrm{LC}}$ with $c_{\mathrm{F}, \mathrm{b}}$ and $c_{\mathrm{D}}$, b, respectively, membrane interfacial concentrations of the draw- and feed-solution can be derived from Eqs. (3) and (4) [21]. Here the diffusivity of $\mathrm{NaCl}, D_{\mathrm{NaCl}}$, is taken to be constant at $1.503 \times 10^{-9} \mathrm{~m}^{2} \mathrm{~s}^{-1}$ [35]. In addition to water flux, salt flux can be calculated by $J_{\mathrm{s}}=B\left(c_{\mathrm{D}, \mathrm{m}}-\mathrm{c}_{\mathrm{F}, \mathrm{m}}\right)$. Three sets of water and salt flux measurements were taken at each salinity range of MD, HI, and UH using the draw-solution concentrations listed in Table 2.

For every salinity range, $B$ and $S$ were simultaneously determined by fitting both experimental water flux $\left(J_{\mathrm{w}}{ }^{\mathrm{EXP}}\right)$ and salt flux $\left(J_{\mathrm{s}}^{\mathrm{EXP}}\right)$ to the calculated $J_{\mathrm{w}}{ }^{\mathrm{CAL}}$ and $J_{\mathrm{s}}{ }^{\mathrm{CAL}}$, using the corresponding $A$ computed in Section 3.4.2. That is, the membrane water permeability is assumed to be independent of solute type and is a function of solution ionic strength. The concatenated residual for both water and salt fluxes, $R s$, is minimized to obtain the $A-S$ combination that best fits the experimental fluxes:

$R s=R s_{\mathrm{w}}+R s_{\mathrm{s}}=\sum_{i=1}^{n}\left(\frac{J_{\mathrm{w}, i}^{\mathrm{EXP}}-J_{\mathrm{w}, i}^{\mathrm{CAL}}}{\bar{J}_{\mathrm{w}}^{\mathrm{EXP}}}\right)^{2}+\sum_{i=1}^{n}\left(\frac{J_{\mathrm{s}, i}^{\mathrm{EXP}}-J_{\mathrm{s}, i}^{\mathrm{CAL}}}{\bar{J}_{\mathrm{s}}^{\mathrm{EXP}}}\right)^{2}$

where $\bar{J}_{\mathrm{S}}^{\mathrm{EXP}}$ is the average of the experimental salt fluxes.

\subsection{Validation of the COMRO transport models}

Water flux in COMRO mode was measured to validate the theoretical model developed in Section 2. One fresh membrane coupon was first compacted under 27.6 bar over $12 \mathrm{~h}$, and then tested in COMRO 
operation, as illustrated in Fig. 2C. Hydraulic pressures of $27.6 \mathrm{bar} \rightarrow$ 20.7 bar $\rightarrow 13.8$ bar $\rightarrow 6.9$ bar (400, 300, 200, and 100 psi, respectively) were applied stepwise on the HC stream. Under each hydraulic pressure, four representative salinities, low, medium, high, and ultrahigh (denoted by LW, MD, HI, and $\mathrm{UH}$, respectively) were examined, with the corresponding bulk-phase salinity combinations $\left(c_{\mathrm{b}}{ }^{\mathrm{LC}}-c_{\mathrm{b}}{ }^{\mathrm{HC}}\right)$ being 0-25 mM, 0.4-0.6 M, 1.2-1.5 M, and 2.5-3.0 M. Steady-state water flux under each pressure-salinity condition was recorded and averaged over $1 \mathrm{~h}$.

\section{Results and discussion}

\subsection{Effects of hydraulic pressure on membrane transport properties}

\subsubsection{Impacts of hydraulic pressure on membrane water permeability}

The behavior of membrane water permeability under different hydraulic pressure operations is discussed here, while the underpinning mechanism is analyzed later in Section 4.1.3, after the presentation of salt permeability trends (Section 4.1.2). Representative profiles of water permeability, $A$, for a pristine TFC osmotic membrane as a function of time and under different hydraulic pressures, $P_{\mathrm{h}}$, are shown in Fig. 3A. Initially, when a low hydraulic pressure of 6.9 bar was applied, $A$ quickly decreased within the first $\approx 30 \mathrm{~min}$ of the test, and then gradually stabilized in $12 \mathrm{~h}$ (blue line). After the 12-h stabilization at 6.9 bar, the pressure was doubled to 13.8 bar, resulting in a marked reduction of $A$ (green line). However, after $P_{\mathrm{h}}$ was increased to $27.6 \mathrm{bar}$, the water permeability held steady and did not drop further (red line).

The steady-state water permeabilities under different hydraulic pressures for the "compaction" operating scenario described above are presented in the left panel of Fig. 3B. Here stabilized $A$ was measured for $60 \mathrm{~min}$ for each pressure and normalized by the stabilized water permeability at $27.6 \mathrm{bar}$, designated as $A^{\text {stb }}$. A substantial drop in water permeability was observed with increasing pressures from 6.9 to 13.8 bar, whereas the impact of further pressurization to 27.6 bar on $A$ was effectively negligible. Once the membrane has stabilized at 27.6 bar (400 psi), A remained relatively constant despite stepwise decreases of the pressure from $27.6 \rightarrow 13.8 \rightarrow 6.9$ bar (middle panel of Fig. 3B). We term this behavior "short-term persistence". After the membrane is relaxed for 20 days from pressurization, water permeability was recovered to almost the pristine value. We term this behavior as "relaxation". Repressurizing the membrane stepwise again decreased $A$ with rising $P_{\mathrm{h}}$, similar to the trend observed in "compaction". This "relaxation and re-compaction" scenario is depicted in the right panel of Fig. 3B. The mechanism causing the observed behavior in response to the different pressurization scenarios is further elaborated in the next two sections.

\subsubsection{Effects of hydraulic pressure on membrane salt permeability}

Steady-state salt and water permeabilities of the pristine membrane under stepwise increase in hydraulic pressures ("compaction" scenario) are presented in Fig. 4A. Similar to the trend of $A$ in the "compaction" scenario (blue circle symbols), $B$ also first declined with an initial increase of hydraulic pressure from 6.9 to 13.8 bar, and then remained relatively constant at higher hydraulic pressures of 20.7 and 27.6 bar (red square symbols). Critically, as shown in Fig. 4B, the ratios of normalized water to salt permeability were very consistent over the
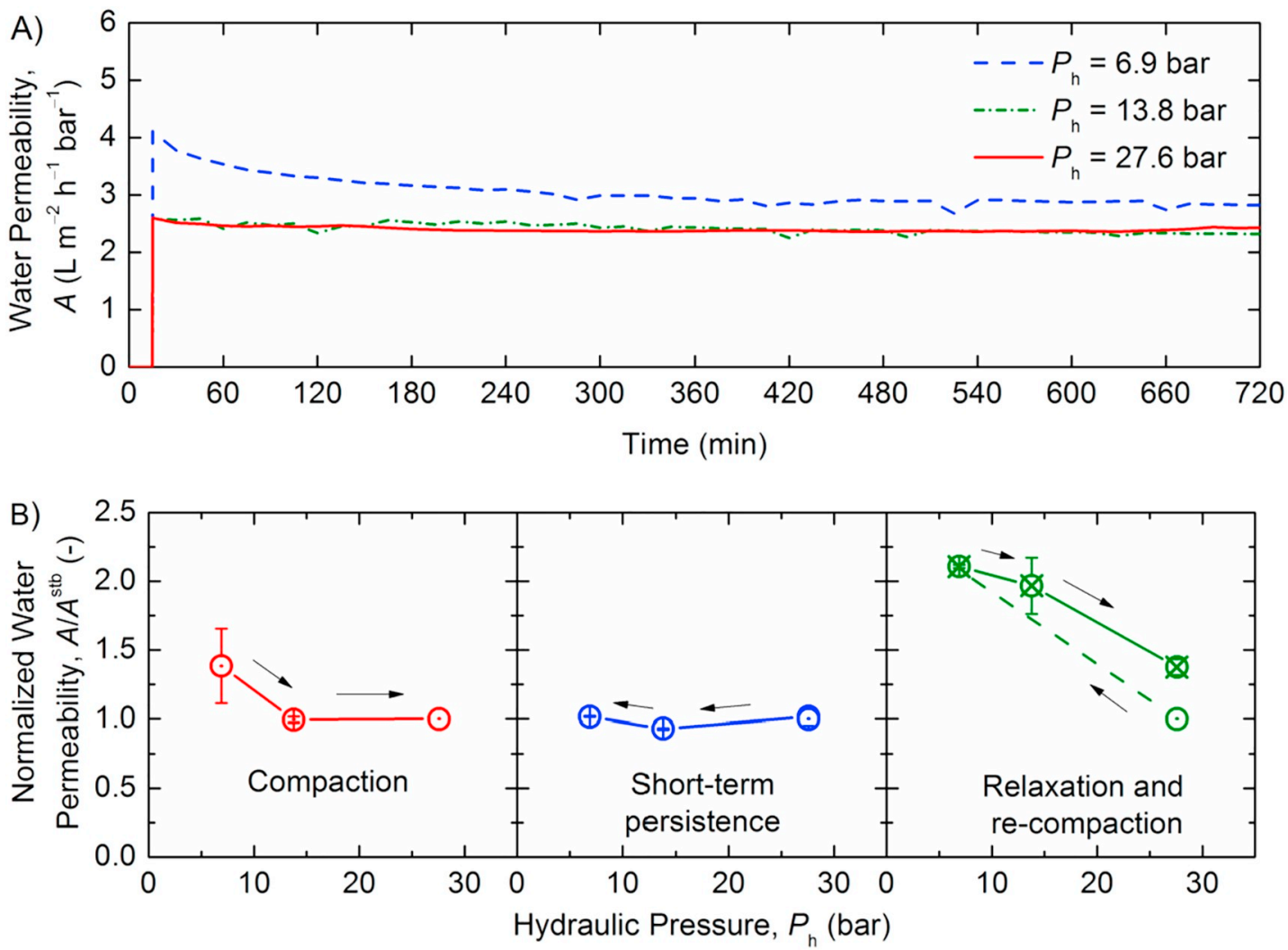

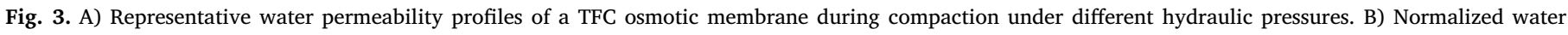

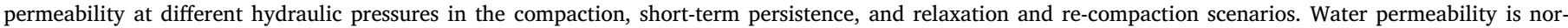

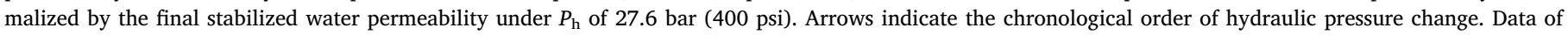

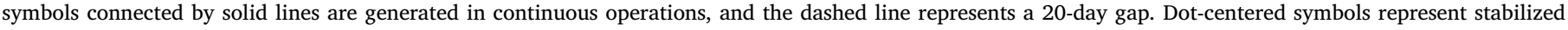

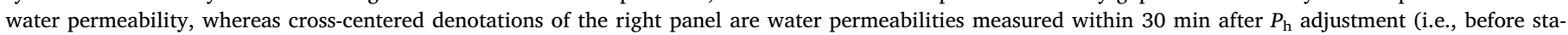

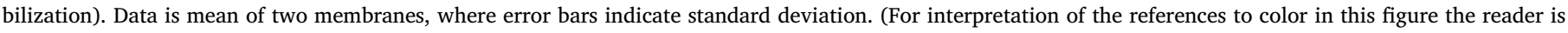
referred to the web version of this article.) 

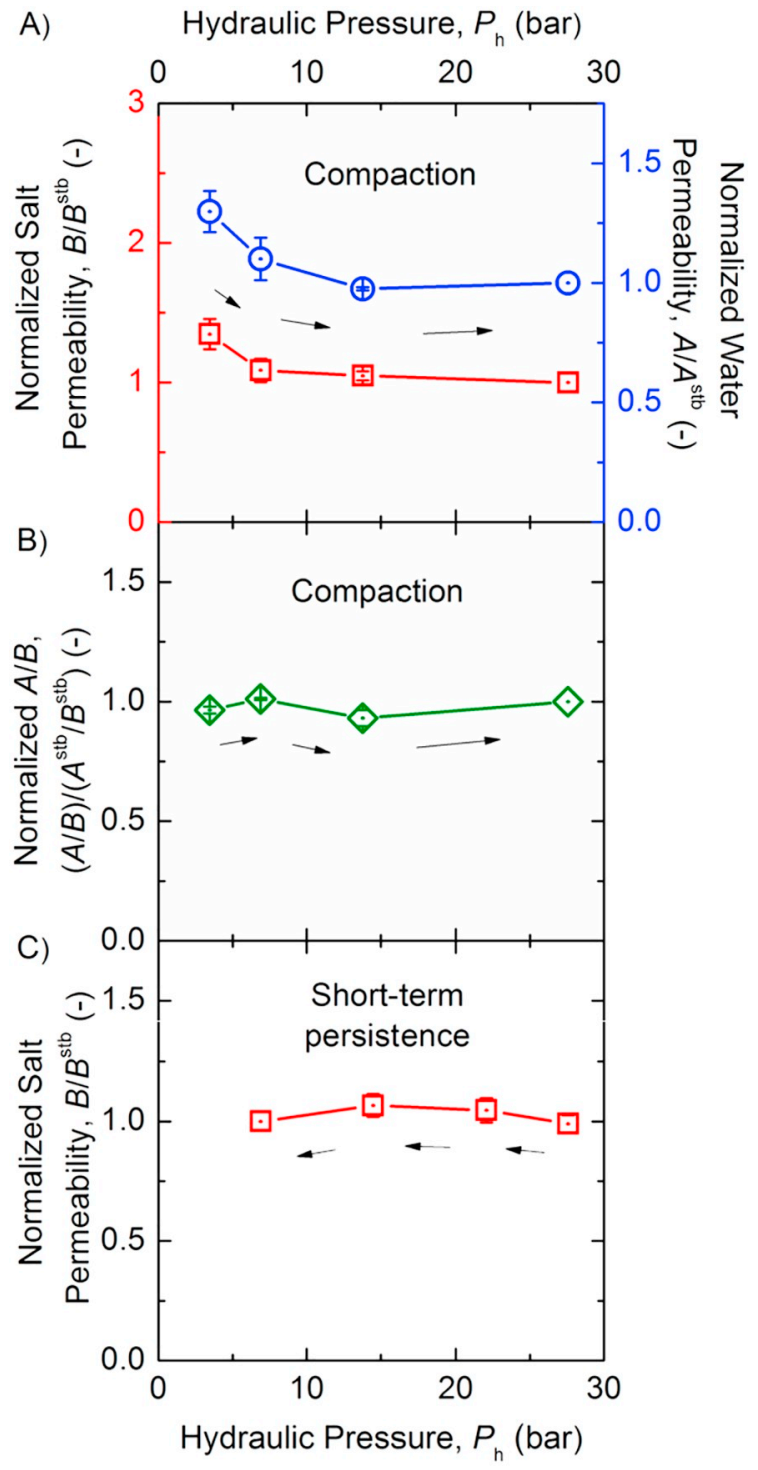

Fig. 4. A) Stabilized water and salt permeabilities normalized by parameter value at 27.6 bar (400 psi), $A / A^{\text {stb }}$ and $B / B^{\text {stb }}$ (blue circle and red square symbols, respectively, for right and left vertical axes), as a function of hydraulic pressure, $P_{\mathrm{h}}$, in the compaction stage. B) Corresponding ratio of normalized water permeability to normalized salt permeability, $(A / B) /\left(A^{\text {stb }} / B^{\text {stb }}\right)$, under different hydraulic pressures. C) Normalized values of stabilized salt permeability as a function of hydraulic pressure in the short-term persistence stage. Arrows indicate the chronological order of hydraulic pressure change. Data is mean of two membranes, whereas error bars indicate standard deviation. (For interpretation of the references to color in this figure, the reader is referred to the web version of this article.)

range of $P_{\mathrm{h}}$ investigated, indicating that selectivity of the membrane active layer for water transport over salt permeation, i.e., $A / B$, is not substantially affected by the hydraulic pressure increase. The practically identical $A / B$ trend strongly suggests that i) a common cause is responsible for the change in transport properties under pressurization and ii) the magnitude of this effect is essentially the same for both $A$ and $B$. We hypothesize that this underlying mechanism is a decrease in membrane effective area for transport, and is further investigated in the next section.

As shown in Fig. 4C, after the membrane is compacted under 27.6 bar, salt permeability also experienced the "short-term persistence" behavior exhibited by water permeability (Fig. 3B), where the membrane properties, $A$ and $B$, maintained constant regardless of the stepwise alleviations in hydraulic pressure. This result indicates that once the TFC osmotic membranes are fully compacted and reached the "short-term persistence" state, both water and salt permeabilities are not affected by short-term changes (on the order of hours) in the hydraulic pressure. From Section 4.2.2 onwards, transport properties of the TFC osmotic membranes reported are for the "short-term persistence" state such that analyses of $A$ and $B$ are insulated from the influences of $P_{\mathrm{h}}$.

\subsubsection{Active-support interface of osmotic membranes under hydraulic pressure}

Cross-sectional SEM micrographs of Fig. 5A show morphological details of the layered structures of the TFC osmotic membrane. The nonporous active layer comprises typical ridge-and-valley structure of polyamide networks $[12,37,38]$. The polysulfone support is highly porous but gradually becomes denser at the top surface towards the active layer, consistent with the nonsolvent-induced phase separation fabrication method [24,37]. At the interface of the active and support layers, the polyamide polymeric matrix interweaves into the polysulfone support layer. We term this porous enmeshment the activesupport "interlayer". After compaction under 27.6 bar (400 psi) hydraulic pressure for $>12 \mathrm{~h}$, the interfacial void space is compressed and the interlayer thickness is drastically decreased, as shown in Fig. 5B. Morphological change of the interlayer under hydraulic pressure can be better illustrated by the schematic in Fig. 5C.

The overall mass transfer resistance of the membrane is the sum of the individual resistances from the contributing layers [39,40], i.e., active layer, active-support interlayer, and porous support. Water permeability of the highly porous support substrate is over two orders of magnitude higher than the overall membrane [41]. Since mass transfer resistance contribution from the support layer is negligible (only $0.5-1 \%$ of the total resistance), even though the porous substrate is deformed by $P_{\mathrm{h}}$, the support layer compaction does not explain the initial quick decline of $A$ (Fig. 3A). The active layer is a principal contributor to overall mass transfer resistance. However, selectivity of the layer is shown in Fig. 4B to be independent of $P_{\mathrm{h}}$, signifying intrinsic structure of the polyamide is fundamentally unaltered. Preservation of the polyamide structure is further supported by a previous study which reported only marginal morphological change of the active layer under mechanical compression of 40 bar [42].

Because water and salt transport across the membrane are not substantially influenced by compaction of the active and support layers, we therefore postulate that the active-support interlayer is critical to mass transfer of the overall membrane. Specifically, we posit that water and salt transport are significantly hindered by morphological changes to the closed interlayer under $P_{\mathrm{h}}$ that essentially reduces the membrane effective area. At relatively low pressures $(<13.8$ bar) of the "compaction" state (Figs. 3B and $4 \mathrm{~A}$ ), the interlayer begins to be mechanically compressed and becomes partially closed, thus blocking off a proportion of the membrane effective area, defined as the area of the selective polyamide layer available for transport, and causing the observed water and salt permeabilities decrease. Increasing $P_{\mathrm{h}}$ further compresses the interlayer, closing off more effective area, as reflected in the continued decline of $A$ and $B$. Deformation of the interlayer is complete between 6.9 and 13.8 bar, and no further compaction takes place with an increase of $P_{\mathrm{h}}$ to 27.6 bar. Hence, there is no additional drop in the membrane permeabilities.

After being fully compacted, the closed portions of the interlayer persist over short timeframes in the "short-term persistence" state despite the lessening of hydraulic pressure. That is, recovery of the activesupport interlayer structure is not instantaneous but, rather, occurs over several hours. As a result, water and salt transport properties of the TFC osmotic membrane in Figs. 3B and 4C are yet to be affected by the hydraulic pressure changes. Morphological changes to the interlayer due to mechanical compaction are reversible and the compressed interlayer gradually recovers after the pressure is released. This is 

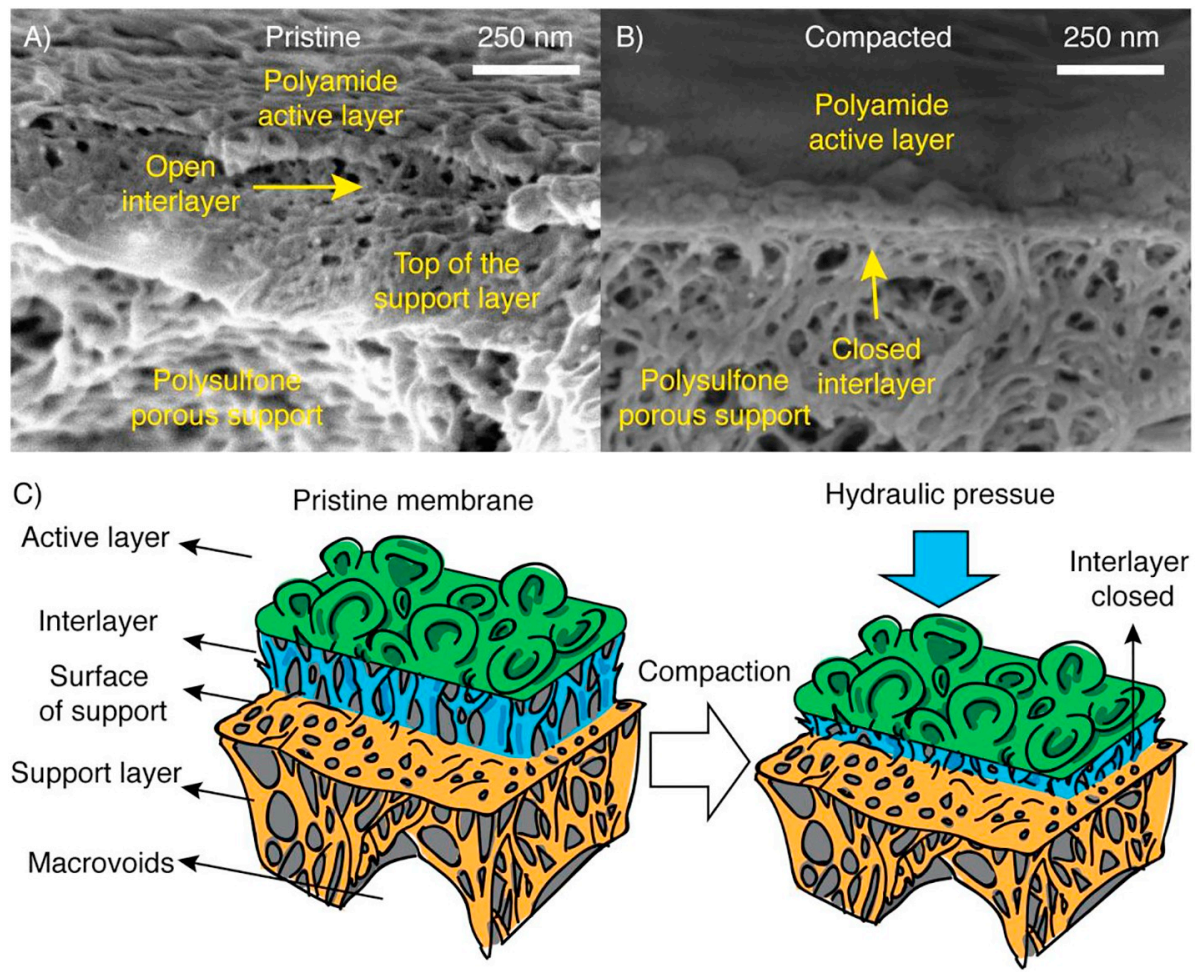

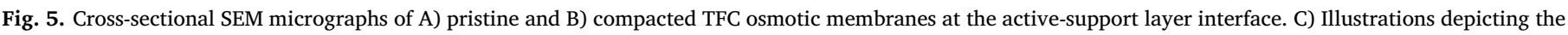
morphological changes in the critical interlayer between the active and support layers of the membrane before and after compaction.

manifested in the high $A$ measured after the membrane is stored at ambient pressure for 20 days. Subsequent pressurization leads to recompaction and closing of interlayer voids again, as represented by the decreasing water permeability in the "relaxation and re-compaction" state (right panel of Fig. 3B). These behaviors are consistent with stress relaxation of polymers [43]. Because changes to the effective membrane area affect the experimentally-measured $A$ and $B$ values by the same degree, the ratio of water to salt permeability is always conserved (Fig. 4B) and is, thus, persuasive evidence in support of the postulated explanation.

\subsection{Influence of salinity on membrane transport and structural parameters}

4.2.1. Membrane structural parameter remains constant across different salinities

Membrane thickness, $t$, and specific pore volume, $v_{\mathrm{p}}$, were evaluated at different $\mathrm{NaCl}$ concentrations to investigate the effect of salinity on the structural parameter, $S$, of the TFC osmotic membrane (Fig. 6A). Across the salinities of 0 to $5 \mathrm{M} \mathrm{NaCl}$ (TDS of 292,500 ppm), $t$ and $v_{\mathrm{p}}$ vary within $\pm 1.8 \%$ and $\pm 4.3 \%$, respectively, with no obvious trends observed. Importantly, the measured deviations are on the same order of magnitude as the variation between different membrane samples. The resulting percentage change in the structural parameter, $\Delta \bar{S}$, deviates within only $\pm 5.0 \%$ in average, as presented in Fig. 6B. Again, $\Delta \bar{S}$ did not exhibit a clear relation with solution salinity, and the spread is within membrane sample variation. Therefore, the range of salinities utilized in COMRO operation would practically have no influence on the structural parameter of the porous support layer, $S$.

\subsubsection{Impacts of salinity on membrane water permeability}

To examine the influence of solution salinity on $A$, water permeability and membrane structural parameter are simultaneously determined, with $B \approx 0$ (negligible $\mathrm{MgSO}_{4}$ permeation) while $S$ is set as a concentration-independent parameter. Water permeabilities at different salinities are shown in Fig. 7 and summarized in Table 3. At medium

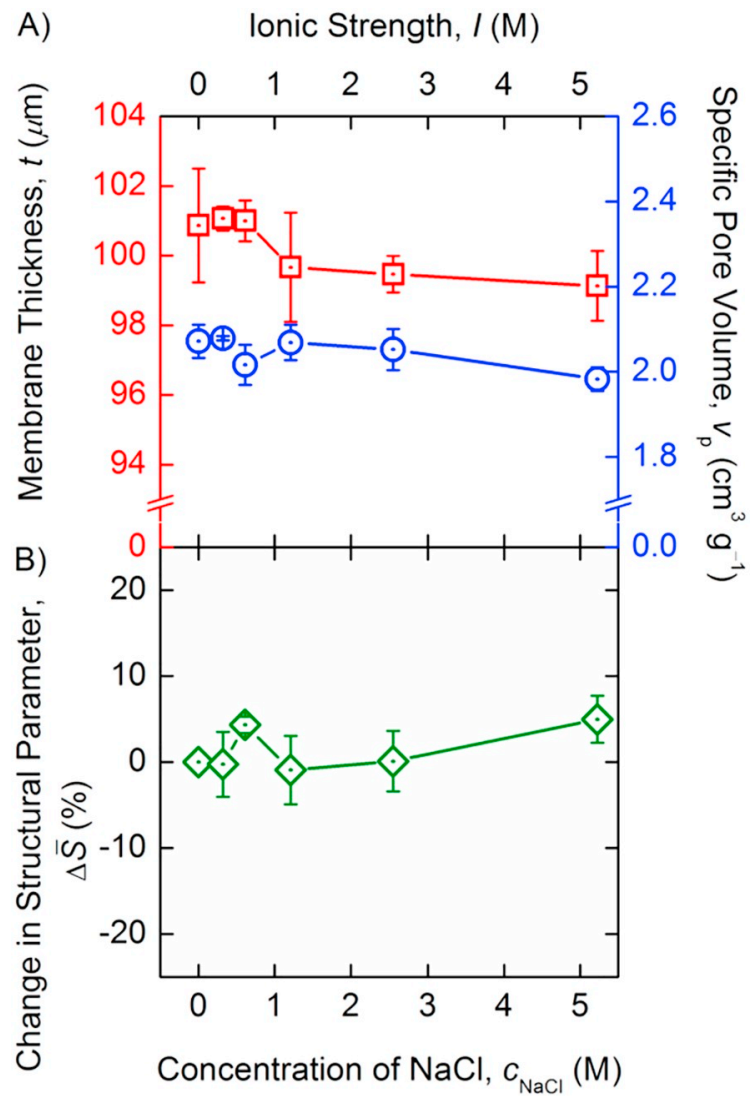

Fig. 6. A) Membrane thickness, $t$ (red square symbols, left vertical axis), specific pore volume, $v_{\mathrm{p}}$ (blue circle symbols, right vertical axis), and B) percent change in membrane structural parameter, $\Delta \bar{S}$, of the TFC osmotic membrane as a function of $\mathrm{NaCl}$ solution concentrations, $c_{\mathrm{NaCl}}$. Ionic strength, $I$, corresponding to $\mathrm{NaCl}$ solution concentration is also presented (top horizontal axis). 


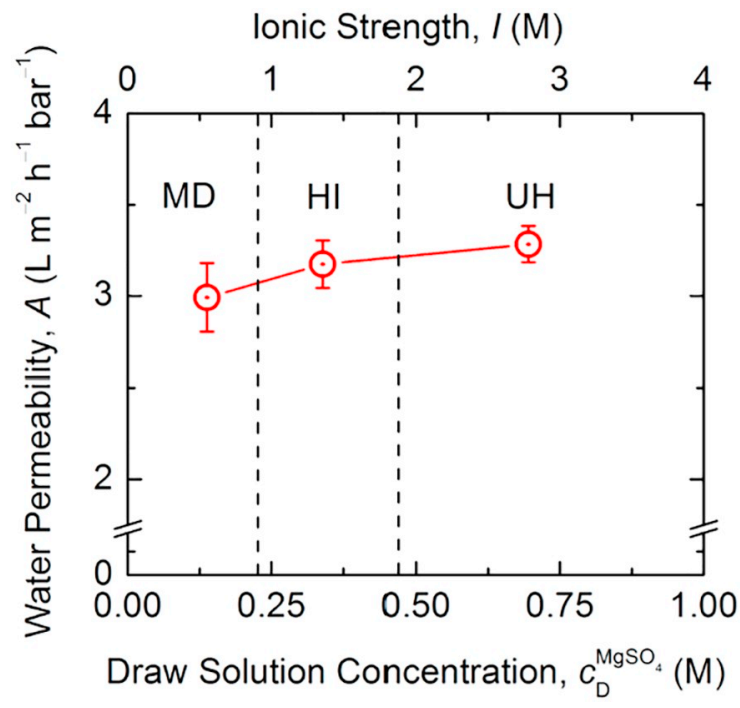

Fig. 7. Water permeability, $A$, at medium salinity (MD), high salinity (HI), and ultrahigh salinity (UH) of different concentrations of $\mathrm{MgSO}_{4}$ draw solution. Ionic strength, $\mathrm{I}$, corresponding to the $\mathrm{MgSO}_{4}$ concentration, $c_{\mathrm{D}} \mathrm{MgSO}_{4}$, is presented in the top horizontal axis. $A$ and $S$ are simultaneously determined by fitting experimental water flux to the theoretical water flux using a least-square method, assuming $B \approx 0$ and $S$ is independent of concentration.

(MD), high (HI), and ultrahigh (UH) salinities, $A$ is $2.99,3.17$, and $3.28 \mathrm{~L} \mathrm{~m}^{-2} \mathrm{~h}^{-1} \mathrm{bar}^{-1}$, respectively. Note that removing the simplifying assumption of nil salt transport yielded practically identical $A$ ( $< \pm 1 \%$ difference), indicating that the assumption of $B \approx 0$ is justified.

Overall, $A$ increased by $9.8 \%$ from MD to UH salinity (specifically, $+6.1 \%$ from MD to $\mathrm{HI}$ salinity and $+3.5 \%$ from HI to UH salinity). Although water permeability is considered as an intrinsic property of the membrane which is independent of ionic strength [22,24,44], previous studies have reported decreased $A$ of cellulose acetate membranes at high ionic strengths in reverse osmosis [45,46]. However, these studies did not exclude effects of changes in $B$ at different ionic strengths, which can, in turn, affect the calculation of $A$. The slight increase in $A$ at high ionic strength observed in this study is in potential conflict with these past studies and is reported for the first time for COMRO. A previous study also indicated increased $A$ in PRO at high salt concentrations [47].

We note that the approximately $10 \%$ increase in $A$ is relatively small in magnitude and can be rendered statistically insignificant by unavoidable variability in experimental measurements. Further, inaccuracies can also likely creep in from the necessary simplifications adopted by the characterization method, e.g., the simplifying assumption of constant diffusivity of $\mathrm{MgSO}_{4}$ at the membrane interface. Despite these uncertainties, the observed increase in $A$ can, indeed, be a real change of the membrane property and further investigations are needed to better understand the phenomenon and underlying mechanisms.

\subsubsection{Influence of salinity on membrane salt permeability}

Fig. 8A shows salt $(\mathrm{NaCl})$ permeability, $B$, at different draw-solution concentrations. In the simultaneous determination of $B$ and $S$, values of
A determined earlier in Section 4.2.2 with $\mathrm{MgSO}_{4}$ draw solutions are used, and $S$ is set as a concentration-independent parameter. Although membrane water permeability may be slightly different when different draw solutes are employed $[48,49]$, the influence on the analysis of $B$ is marginal and would not significantly alter the trends of Fig. 8A. At medium, high, and ultrahigh salinities, $B$ is 2.03, 2.52, and $2.88 \mathrm{~L} \mathrm{~m}^{-2} \mathrm{~h}^{-1}$, respectively (Table 3 ). Overall, $B$ at ultrahigh salinity is $41.9 \%$ higher than that at medium salinity. Unlike the $A$ and $B$ trends under hydraulic pressurization, where the loss of effective surface area of the active-support interlayer resulted in a constant $A / B$ ratio, water and salt permeabilities did not change in the same proportion with greater salinities (Fig. 8B). Even though both $A$ and $B$ increase with rising salinities (Figs. 7 and $8 \mathrm{~A}$ ), $A / B$ decreases $22.1 \%$, indicating that $B$ increases more considerably than $A$, thus substantiating the detrimental effect of high salinity on membrane selectivity.

Increase of $B$ at elevated salinities had been reported for another osmotically-driven membrane process of pressure-retarded osmosis (PRO) [47]. A possible explanation for this faster salt transport at high salinities is the decrease in the radius of hydrated ions. Previous studies have suggested that hydration numbers of ions decrease at higher concentrations $[50,51]$. The smaller hydrated ions permeate more rapidly through water swollen polymers [22] and increased salt permeabilities are, therefore, observed at high salinities. Another possible explanation for the greater salt transport at higher salinities is the screening of membrane active layer charges at high ionic strengths $[22,24,52]$. In relatively low-concentration electrolyte solutions, because of the deprotonation of non-crosslinked carboxyl groups in the polyamide, the membrane active layer is negatively charged [22,24]. The charged functional groups electrostatically repel co-ions (i.e., anions) and transport of the counterion is also hindered to maintain charge neutrality. Thus, the electrolyte is better rejected by the charged active layer. However, as concentration increases, the membrane charges are gradually saturated by the sorption of counterions, lowering the effective charge density and electrolyte repulsion is therefore screened [53]. Overall, elevated salt transport is observed at high salinities.

\subsection{Validation of the model for water and salt transport in COMRO}

To validate the COMRO transport model established in the Theory section, experimental and calculated water fluxes, $J_{\mathrm{w}}{ }^{\mathrm{EXP}}$ and $J_{\mathrm{w}}{ }^{\mathrm{CAL}}$, respectively, are compared in Fig. 9. The steady-state $A$ and $B$ determined by the method described in Section 3.2 and constant $S$ value of $394.5 \mu \mathrm{m}$ estimated in Sections 4.2 were used for prediction of water flux using Eqs. (3) and (4). We note that varying $S$ within $\pm 100 \mu \mathrm{m}$ has only marginal influence on the calculated water fluxes.

Across the entire salinity range, experimental water fluxes matched the predicted values very well, with the exception of larger deviations between $J_{\mathrm{w}}{ }^{\mathrm{EXP}}$ and $J_{\mathrm{w}}{ }^{\mathrm{CAL}}$ for higher hydraulic pressures, where calculated $J_{\mathrm{w}}$ underpredict actual fluxes. We found that a better $J_{\mathrm{w}}{ }^{\mathrm{EXP}}-J_{\mathrm{w}}{ }^{\mathrm{CAL}}$ agreement can be attained if a higher $B$ value is introduced to the model, whereas adjusting values of $A$ and/or $S$ did not yield significant effects. This suggests that actual salt transport across the active layer at larger $\Delta P$ is likely to be substantially higher than theoretical prediction, thus mitigating the detrimental effect of ICP in the support layer and resulting in higher actual $J_{\mathrm{w}}$. As shown in Section 4.2, the effect of increasing $\Delta P$ on membrane salt permeability in the "short-term

Table 3

Membrane transport and structural properties at different salinities.

\begin{tabular}{|c|c|c|c|c|}
\hline Salinity & Ionic strength, $I(\mathrm{M})$ & Water permeability, $A\left(\mathrm{~L} \mathrm{~m}^{-2} \mathrm{~h}^{-1} \mathrm{bar}^{-1}\right)$ & $\mathrm{NaCl}$ permeability, $B\left(\mathrm{~L} \mathrm{~m}^{-2} \mathrm{~h}^{-1}\right)$ & Structural parameter, $S(\mu \mathrm{m})$ \\
\hline Medium & 0.55 & $2.99 \pm 0.19$ & $2.03 \pm 0.08$ & $394.53 \pm 0.04$ \\
\hline High & 1.36 & $3.17 \pm 0.13$ & $2.52 \pm 0.08$ & \\
\hline Ultrahigh & 2.78 & $3.28 \pm 0.10$ & $2.88 \pm 0.15$ & \\
\hline
\end{tabular}




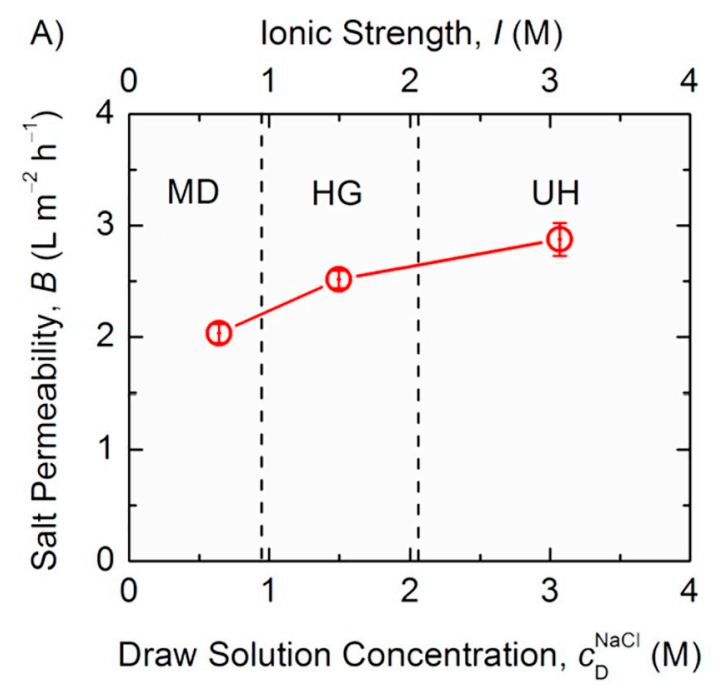

B)

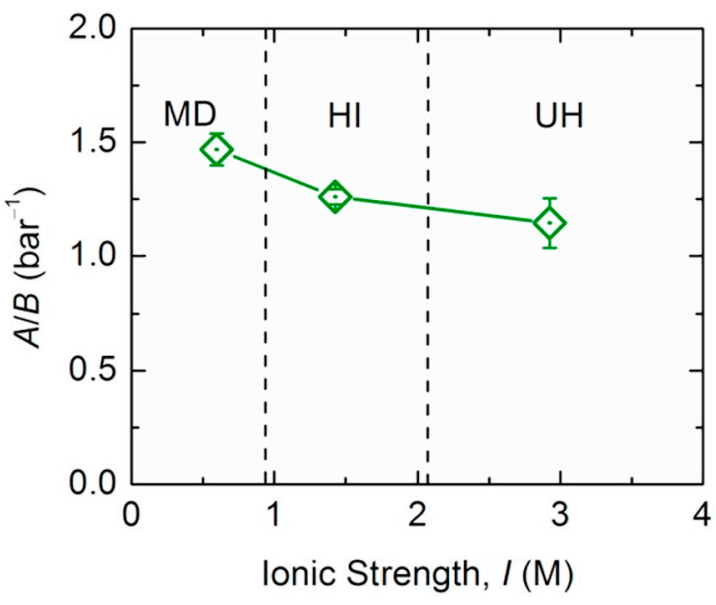

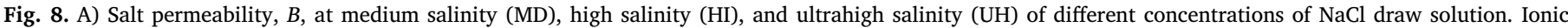

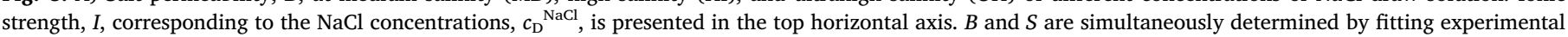

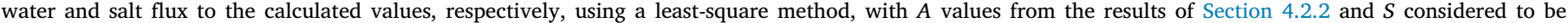
independent of concentration. B) Ratio of water permeability to salt permeability, $A / B$, at different salinities or, equivalently, ionic strength.

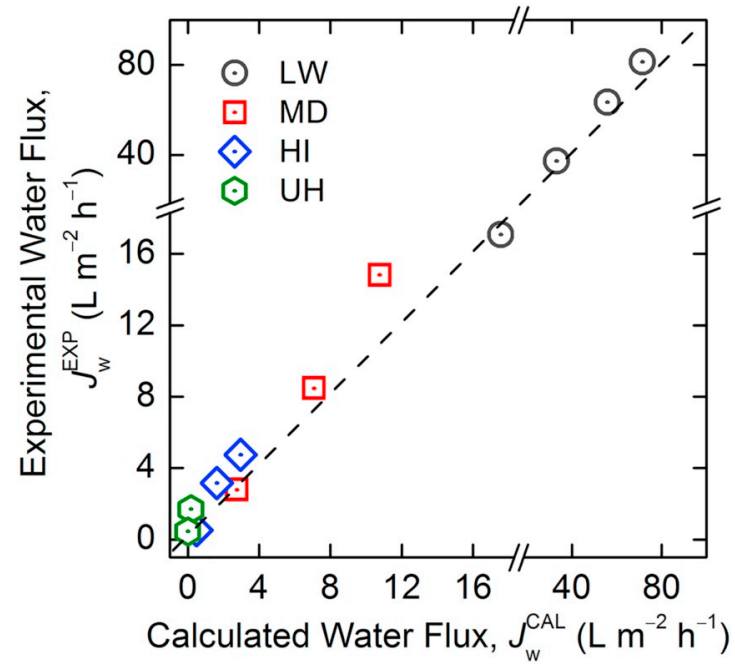

Fig. 9. Comparison between experimental water flux, $J_{\mathrm{w}}{ }^{\mathrm{EXP}}$, and calculated water flux, $J_{\mathrm{w}}{ }^{\mathrm{CAL}}$ (vertical and horizontal axes, respectively), using the COMRO model under different hydraulic pressures at low salinity (LW, grey circle symbols), medium salinity (MD, red square symbols), high salinity (HI, blue diamond symbols), and ultrahigh salinity (UH, green hexagon symbols). The dashed $45^{\circ}$ line denotes perfect agreement between experimental and theoretical values.

persistence" state of RO is insignificant (Fig. 4C). Therefore, the deviations between experimental and calculated fluxes are likely due to an inherent limitation of the characterization method used in this study to accurately determine $B$. Specifically, $B$ was analyzed with only one side of the membrane exposed to the high salinities (depicted by Fig. 2B and detailed in Section 3.5), whereas both interfaces of the membrane experience high salinities in COMRO (Fig. 2C).

This substantially increased $B$ cannot be adequately described by the classic solution-diffusion transport model widely accepted to explain transport phenomena in salt-rejecting membranes (i.e., RO and FO membranes), due to the atypical operating conditions of COMRO. Rather, the underlying assumptions of the solution-diffusion framework can limit accurate prediction of water and salt transport in COMRO [22-24,54,55]. First, the solution-diffusion model assumes that solute transport across a membrane matrix is purely driven by the chemical potential gradient (approximately equivalent to the solute concentration gradient), neglecting a possible variation of pressure within the nonporous active layer. However, significantly enhanced salt leakage through the TFC membrane has been observed in pressure-retarded osmosis (PRO), where $\Delta P$ is applied down the salt transport concentration gradient $[47,56]$, i.e., similar operation to COMRO. The unexpectedly high salt leakage indicates that the pressure gradient across the active layer could be assisting salt transport by convection, hence resulting in elevated salt permeation. This can also explain the larger $J_{\mathrm{w}}{ }^{\text {EXP }} J_{\mathrm{w}}{ }^{\text {CAL }}$ deviations at higher $\Delta P$ in COMRO. Second, solventsolute interactions are not considered in the classical solution-diffusion model, with water and salt transport being treated as independent components in osmotically-driven membrane processes. However, significant solvent-solute coupling effects have been reported in FO [57], where diffusive salt transport is hindered by convective water flow in the opposite direction. In COMRO, salt transport can therefore be enhanced by water flux since $J_{\mathrm{w}}$ and $J_{\mathrm{s}}$ are in the same direction.

\section{Implications for COMRO and osmotic membrane processes}

In this study, a theoretical model is established to understand water and salt transport in COMRO hypersaline desalination. Transport and structural properties of the TFC osmotic membrane are experimentally characterized to elucidate the influence of different pressure and salinity conditions representative of COMRO operation. While the study is motivated by COMRO, the implications revealed are also applicable on a broader perspective to all osmotic membrane processes, i.e., reverse osmosis (RO), forward osmosis (FO), and pressure-retarded osmosis (PRO).

In the systematic investigation of membrane water and salt permeabilities under different hydraulic pressures, the TFC osmotic membrane experienced reversible decline in both $A$ and $B$ as $\Delta P$ increases, while maintaining the same selectivity of the active layer, $A / B$. In the "shortterm persistence" state, the TFC osmotic membrane exhibits constant $A$ and $B$ regardless of transitory pressure change (on the order of hours), indicating that water and salt transport in this regime are not sensitive to $\Delta P$. However, on longer timescales, i.e., the order of days, the polymeric membrane compacts/relaxes under pressurization/depressurization, hence altering $A$ and $B$. These findings have important implications for osmotic membrane characterizations, as well as actual operation. For accurate determination of transport properties, TFC osmotic membranes 
should be first compacted up to the "short-term persistence" state and maintained at the same $\Delta P$ to attain stable parameters, before initiating characterization protocols. For applications with temporal variability in hydraulic pressure, such as reverse osmosis desalination powered by the fluctuating input of solar photovoltaics [58-60], membrane water and salt permeabilities are effectively constant for short-duration fluctuations, e.g., due to cloud cover, but will be altered for longer term changes, for example, diurnal variations in solar irradiance.

Morphological change of the active-support interlayer under hydraulic pressure was found to be a principle factor governing $A$ and $B$. The reversible reductions of $A$ and $B$ under increasing hydraulic pressures are attributed to deformation of the interlayer that leads to partial blockage of the active layer effective area. Intrinsic water and salt transport of the active layer are unchanged and, thus, $A / B$ is preserved. This finding provides insights into the membrane transport phenomena and also has implications for the development of high-performance membranes. The design and fabrication of composite membranes with highly porous and mechanically robust active-support interlayer is critical to achieve high water permeability and stable salt rejection for COMRO and other osmotic membrane processes that employ hydraulic pressurization, including RO, PRO, and osmotically assisted RO [61].

In the investigation of the influences of salinity on membrane structural and transport properties, the membrane structural parameter, $S$, is shown to be independent of salt concentration. As salinity increases, both water and salt permeabilities are elevated, with $B$ increasing disproportionally larger than $A$. These findings highlight the significance of the strong influence of high salinities on salt permeability in membrane processes employing solutions of high ionic strength. In applications such as COMRO, FO, PRO, high-pressure RO, and low-salt-rejection RO [67], the hypersaline conditions will lower salt selectivity and consequently cause higher-than-expected salt flux across the membrane. Further studies are needed to better understand the underlying mechanisms and inform the development of salinityinsensitive membranes.

Validity of the presented transport model is assessed with results from COMRO experiments. The good agreement between experimental and predicted water fluxes validates the COMRO model, as well as substantiates the accuracy of the membrane properties determined from the characterization approaches employed here. The poorer predictability of the model at higher $\Delta P$ is likely due to substantially elevated $B$ in COMRO, underlining possible deficiencies in the classical solutiondiffusion mechanism. More rigorous models are, therefore, needed for better understanding of transmembrane mass transfer in COMRO and other processes that utilize elevated pressurization, such as high-pressure RO.

Although the performance of all osmotically-driven membrane processes, including COMRO, are limited by internal concentration polarization (ICP) $[19,62,63]$, this study reveals that the detrimental effects of ICP in COMRO are mitigated by salt transport, which is in the same direction of water permeation (in contrast to FO where salt and water permeation are in opposite directions). Since the aim of bilateral countercurrent stages in COMRO is to dilute the influent feed stream (instead of rejecting salt to produce high-quality water), the forward salt transport can be beneficial for increasing water permeation to dilute the high-salinity feed. Hence, counterintuitively, salt permeation which is typically deleterious is taken advantage of to enhance performance of high-salinity desalination in COMRO. Further, while developing membranes with smaller $S$ is vital for osmotically-driven membrane processes, i.e., PRO and FO [62,64-66], findings of this study indicate that tailoring membrane active layer properties, $A$ and $B$, is more important for optimizing COMRO performance. This study sheds light on transport in COMRO and provides important implications for advancement of the emerging desalination technology.
Nomenclature

\section{Acronyms}

BCC bilateral countercurrent

COMRO cascading osmotically mediated reverse osmosis

ECP external concentration polarization

FO forward osmosis

HI high salinity

ICP internal concentration polarization

LW low salinity

MD medium salinity

PRO pressure-retarded osmosis

TFC thin-film composite

$\mathrm{UH}$ ultrahigh salinity

Symbols

a thickness of the active layer of membrane composite $(\mu \mathrm{m})$

A membrane water permeability $\left(\mathrm{L} \mathrm{m}^{-2} \mathrm{~h}^{-1} \mathrm{bar}^{-1}\right)$

$A^{\text {stb }} \quad$ stabilized water permeability $\left(\mathrm{L} \mathrm{m}^{-2} \mathrm{~h}^{-1} \mathrm{bar}^{-1}\right)$

$B \quad$ membrane salt permeability $\left(\mathrm{L} \mathrm{m}^{-2} \mathrm{~h}^{-1}\right)$

$B^{\text {stb }} \quad$ stabilized salt permeability $\left(\mathrm{L} \mathrm{m}^{-2} \mathrm{~h}^{-1}\right)$

$c$ concentration (M)

$c_{\mathrm{b}}{ }^{\mathrm{HC}}$ bulk-phase solute concentration of the high-concentration stream (M)

$c_{\mathrm{b}}{ }^{\mathrm{LC}} \quad$ bulk-phase solute concentration of the low-concentration stream (M)

$c_{\mathrm{D}}, \mathrm{b} \quad$ bulk-phase solute concentration of the draw solution (M)

$c_{\mathrm{D}, \mathrm{m}}$ membrane interfacial solute concentration of the draw solution (M)

$c_{\mathrm{F}, \mathrm{b}} \quad$ bulk-phase solute concentration of the feed solution (M)

$c_{\mathrm{F}, \mathrm{m}}$ membrane interfacial solute concentration of the feed solution $(\mathrm{M})$

$c_{\mathrm{m}}{ }^{\mathrm{HC}}$ membrane interfacial solute concentration of the high-concentration stream $(\mathrm{M})$

$c_{\mathrm{m}}{ }^{\mathrm{LC}} \quad$ membrane interfacial solute concentration of the low-concentration stream $(\mathrm{M})$

$D \quad$ bulk-phase diffusion coefficient of electrolyte solute $\left(\mathrm{m}^{2} \mathrm{~s}^{-1}\right)$

$D_{\text {eff }}^{\text {ECP }}$ effective diffusion coefficient in the ECP region $\left(\mathrm{m}^{2} \mathrm{~s}^{-1}\right)$

$D_{\text {eff }}^{\text {ICP }}$ effective diffusion coefficient in the ICP region $\left(\mathrm{m}^{2} \mathrm{~s}^{-1}\right)$

I ionic strength (M)

$J_{\mathrm{s}} \quad$ salt flux $\left(\mathrm{mmol} \mathrm{m} \mathrm{m}^{-2} \mathrm{~h}^{-1}\right)$

$J_{\mathrm{w}} \quad$ water flux $\left(\mathrm{L} \mathrm{m}^{-2} \mathrm{~h}^{-1}\right)$

$J_{\mathrm{s}}^{\mathrm{EXP}} \quad$ experimental salt flux $\left(\mathrm{mmol} \mathrm{m}^{-2} \mathrm{~h}^{-1}\right)$

$J_{\mathrm{S}}{ }^{\mathrm{CAL}} \quad$ calculated salt flux $\left(\mathrm{mmol} \mathrm{m} \mathrm{m}^{-2} \mathrm{~h}^{-1}\right)$

$J_{\text {EXP }}$

$J_{\text {w }}$ CAL

$k$ experimental water flux $\left(\mathrm{L} \mathrm{m}^{-2} \mathrm{~h}^{-1}\right)$ calculated water flux $\left(\mathrm{L} \mathrm{m}^{-2} \mathrm{~h}^{-1}\right)$ mass transfer coefficient of the ECP boundary layer $\left(\mathrm{L} \mathrm{m}^{-2} \mathrm{~h}^{-1}\right)$

$m_{\mathrm{d}} \quad$ weight of the dry membrane $(\mathrm{g})$

$m_{\mathrm{w}} \quad$ weight of the wetted membrane $(\mathrm{g})$

$P_{\mathrm{h}} \quad$ applied hydraulic pressure (bar)

$\Delta P \quad$ transmembrane hydraulic pressure difference (bar)

$R \quad$ observed salt rejection (\%)

Rs concatenated residual of both water and salt fluxes

$R s_{\mathrm{S}} \quad$ residual sum of normalized squares of salt flux

$R s_{\mathrm{w}} \quad$ residual sum of normalized squares of water flux

$S \quad$ structural parameter of the membrane support $(\mu \mathrm{m})$

$\Delta \bar{S} \quad$ percentage change in membrane structural parameter (\%)

$t \quad$ thickness of the support layer of membrane composite $(\mu \mathrm{m})$

$v_{\mathrm{p}} \quad$ specific pore volume $\left(\mathrm{cm}^{3} \mathrm{~g}^{-1}\right)$

$x \quad$ position across the membrane $(\mu \mathrm{m})$ 


\section{Greek letters}

$\alpha \quad$ virial coefficients for the osmotic pressure function

$\delta \quad$ thickness of the ECP boundary layer $(\mu \mathrm{m})$

$\varepsilon \quad$ porosity of the membrane support (\%)

$\pi \quad$ osmotic pressure (bar)

$\rho_{\mathrm{NaCl}}$ density of the $\mathrm{NaCl}$ solution $\left(\mathrm{g} \mathrm{cm}^{-3}\right)$

$\tau \quad$ pore tortuosity of the membrane support

\section{Dimensionless groups}

$\bar{\lambda}_{\mathrm{S}} \quad$ normalized membrane structural parameter

$\bar{\lambda}_{\mathrm{t}} \quad$ normalized thickness of the membrane support

$\bar{\lambda}_{\mathrm{v}} \quad$ normalized specific pore volume

$\bar{\lambda}_{\varepsilon} \quad$ normalized porosity

$\bar{\lambda}_{\tau} \quad$ normalized tortuosity

\section{Superscripts and subscripts}

b bulk phase

CAL calculated using theoretical models

d dry

D draw-solution side

eff effective

EXP experimental data

F Feed-solution side

HC high-concentration side

h hydraulic

LC low-concentration side

$\mathrm{m}$ membrane interfacial

$\mathrm{P} \quad$ permeate-solution side

s salt

stb stabilized

w water/wetted

$0 \quad$ zero salinity

\section{CRediT authorship contribution statement}

Xi Chen: Conceptualization, Methodology, Data curation, Software, Formal analysis, Investigation, Writing - original draft, Writing - review \& editing, Visualization.Chanhee Boo: Methodology, Formal analysis, Writing - original draft.Ngai Yin Yip: Conceptualization, Methodology, Formal analysis, Writing - original draft, Writing - review \& editing, Supervision.

\section{Declaration of competing interest}

The authors declare no known financial and personal relationships with other people or organizations that could inappropriately influence (bias) this work.

\section{References}

[1] B.K. Pramanik, L. Shu, V. Jegatheesan, A review of the management and treatment of brine solutions, Environ. Sci.: Water Res. Technol. 3 (2017) 625-658.

[2] N. Ahmad, R.E. Baddour, A review of sources, effects, disposal methods, and regulations of brine into marine environments, Ocean Coast. Manag. 87 (2014) 1-7.

[3] C.E. Clark, J.A. Veil, Produced Water Volumes and Management Practices in the United States, Argonne National Lab.(ANL), Argonne, IL (United States), 2009.

[4] D.L. Shaffer, L.H. Arias Chavez, M. Ben-Sasson, S. Romero-Vargas Castrillón, N.Y. Yip, M. Elimelech, Desalination and reuse of high-salinity shale gas produced water: drivers, technologies, and future directions, Environ. Sci. Technol. 47 (2013) 9569-9583.

[5] K.B. Gregory, R.D. Vidic, D.A. Dzombak, Water management challenges associated with the production of shale gas by hydraulic fracturing, Elements 7 (2011) $181-186$.

[6] T. Tong, M. Elimelech, The global rise of zero liquid discharge for wastewater management: drivers, technologies, and future directions, Environ. Sci. Technol. 50 (2016) 6846-6855.
[7] P.V. Brady, R.J. Kottenstette, T.M. Mayer, M.M. Hightower, Inland desalination: challenges and research needs, J. Contemp. Water Res. Educ. 132 (2005) 46-51.

[8] S. Renou, J.G. Givaudan, S. Poulain, F. Dirassouyan, P. Moulin, Landfill leachate treatment: review and opportunity, J. Hazard. Mater. 150 (2008) 468-493.

[9] V. Karanikola, C. Boo, J. Rolf, M. Elimelech, Engineered slippery surface to mitigate gypsum scaling in membrane distillation for treatment of hypersaline industrial wastewaters, Environ. Sci. Technol. 52 (2018) 14362-14370.

[10] G.P. Thiel, E.W. Tow, L.D. Banchik, H.W. Chung, Energy consumption in desalinating produced water from shale oil and gas extraction, Desalination 366 (2015) 94-112.

[11] D. Brogioli, F. La Mantia, N.Y. Yip, Thermodynamic analysis and energy efficiency of thermal desalination processes, Desalination 428 (2018) 29-39.

[12] M. Elimelech, W.A. Phillip, The future of seawater desalination: energy, technology, and the environment, Science 333 (2011) 712-717.

[13] C. Fritzmann, J. Löwenberg, T. Wintgens, T. Melin, State-of-the-art of reverse osmosis desalination, Desalination 216 (2007) 1-76.

[14] L.F. Greenlee, D.F. Lawler, B.D. Freeman, B. Marrot, P. Moulin, Reverse osmosis desalination: water sources, technology, and today's challenges, Water Res. 43 (2009) 2317-2348.

[15] R. Rautenbach, T. Linn, L. Eilers, Treatment of severely contaminated waste water by a combination of RO, high-pressure RO and NF-potential and limits of the process, J. Membr. Sci. 174 (2000) 231-241.

[16] K.L. Hickenbottom, J. Vanneste, M. Elimelech, T.Y. Cath, Assessing the current state of commercially available membranes and spacers for energy production with pressure retarded osmosis, Desalination 389 (2016) 108-118.

[17] B.D. Coday, D.M. Heil, P. Xu, T.Y. Cath, Effects of transmembrane hydraulic pressure on performance of forward osmosis membranes, Environ. Sci. Technol. 47 (2013) 2386-2393.

[18] D.M. Davenport, A. Deshmukh, J.R. Werber, M. Elimelech, High-pressure reverse osmosis for energy-efficient hypersaline brine desalination: current status, design considerations, and research needs, Environ. Sci. Technol. Let. 5 (2018) 467-475.

[19] X. Chen, N.Y. Yip, Unlocking high-salinity desalination with cascading osmotically mediated reverse osmosis: energy and operating pressure analysis, Environ. Sci. Technol. 52 (2018) 2242-2250.

[20] A. Deshmukh, N.Y. Yip, S. Lin, M. Elimelech, Desalination by forward osmosis: identifying performance limiting parameters through module-scale modeling, J. Membr. Sci. 491 (2015) 159-167.

[21] A. Tiraferri, N.Y. Yip, A.P. Straub, S.R.-V. Castrillon, M. Elimelech, A method for the simultaneous determination of transport and structural parameters of forward osmosis membranes, J. Membr. Sci. 444 (2013) 523-538.

[22] G.M. Geise, D.R. Paul, B.D. Freeman, Fundamental water and salt transport properties of polymeric materials, Prog. Polym. Sci. 39 (2014) 1-42.

[23] J.G. Wijmans, R.W. Baker, The solution-diffusion model: a review, J. Membr. Sci. 107 (1995) 1-21.

[24] R.W. Baker, Membrane Technology and Applications, John Wiley \& Sons, 2012.

[25] R.A. Robinson, R.H. Stokes, Electrolyte Solutions, Courier Corporation, 2002.

[26] N.Y. Yip, A. Tiraferri, W.A. Phillip, J.D. Schiffman, L.A. Hoover, Y.C. Kim, M. Elimelech, Thin-film composite pressure retarded osmosis membranes for sustainable power generation from salinity gradients, Environ. Sci. Technol. 45 (2011) 4360-4369.

[27] S. Kook, C.D. Swetha, J. Lee, C. Lee, T. Fane, I.S. Kim, Forward osmosis membranes under null-pressure condition: do hydraulic and osmotic pressures have identical nature? Environ. Sci. Technol. 52 (2018) 3556-3566.

[28] E.M.V. Hoek, A.S. Kim, M. Elimelech, Influence of crossflow membrane filter geometry and shear rate on colloidal fouling in reverse osmosis and nanofiltration separations, Environ. Eng. Sci. 19 (2002) 357-372.

[29] S.S. Manickam, J.R. McCutcheon, Understanding mass transfer through asymmetric membranes during forward osmosis: a historical perspective and critical review on measuring structural parameter with semi-empirical models and characterization approaches, Desalination 421 (2017) 110-126.

[30] V.D. Bruggeman, Berechnung verschiedener physikalischer Konstanten von heterogenen Substanzen. I. Dielektrizitätskonstanten und Leitfähigkeiten der Mischkörper aus isotropen Substanzen, Ann. Phys. 416 (1935) 636-664.

[31] L. Shen, Z. Chen, Critical review of the impact of tortuosity on diffusion, Chem. Eng. Sci. 62 (2007) 3748-3755.

[32] A. Berson, H. Choi, J.G. Pharoah, Determination of the effective gas diffusivity of a porous composite medium from the three-dimensional reconstruction of its microstructure, Phys. Rev. E 83 (2011) 026310.

[33] R. McKinney Jr., J.H. Rhodes, Aromatic polyamide membranes for reverse osmosis separations, Macromolecules 4 (1971) 633-637.

[34] M. Cheryan, Ultrafiltration and Microfiltration Handbook, CRC press, 1998.

[35] V.M.M. Lobo, Mutual diffusion coefficients in aqueous electrolyte solutions (technical report), Pure Appl. Chem. 65 (1993) 2613-2640.

[36] M. Newville, T. Stensitzki, D.B. Allen, M. Rawlik, A. Ingargiola, A. Nelson, LMFIT: non-linear least-square minimization and curve-fitting for Python, Astrophysics Source Code Library (2016) 1606.014.

[37] R.J. Petersen, Composite reverse osmosis and nanofiltration membranes, J. Membr. Sci. 83 (1993) 81-150.

[38] R.J. Petersen, J.E. Cadotte, Thin film composite reverse osmosis membranes, Handbook of Industrial Membrane Technology, 1990, pp. 307-348.

[39] H. Ohya, An expression method of compaction effects on reverse osmosis membranes at high pressure operation, Desalination 26 (1978) 163-174.

[40] K.Y. Wang, R.C. Ong, T.-S. Chung, Double-skinned forward osmosis membranes for reducing internal concentration polarization within the porous sublayer, Ind. Eng. Chem. Res. 49 (2010) 4824-4831.

[41] A.K. Ghosh, E.M.V. Hoek, Impacts of support membrane structure and chemistry on 
polyamide-polysulfone interfacial composite membranes, J. Membr. Sci. 336 (2009) 140-148.

[42] M. Aghajani, M. Wang, L.M. Cox, J.P. Killgore, A.R. Greenberg, Y. Ding, Influence of support-layer deformation on the intrinsic resistance of thin film composite membranes, J. Membr. Sci. 567 (2018) 49-57.

[43] P.C. Hiemenz, T.P. Lodge, Polymer Chemistry, CRC press, 2007.

[44] J.R. McCutcheon, R.L. McGinnis, M. Elimelech, Desalination by ammonia-carbon dioxide forward osmosis: influence of draw and feed solution concentrations on process performance, J. Membr. Sci. 278 (2006) 114-123.

[45] W. Pusch, Transport behaviour of asymmetric cellulose acetate membranes in dialysis and hyperfiltration, Permeability of Plastic Films and Coatings, Springer, 1974, pp. 233-257.

[46] H.A. Massaldi, C.H. Borzi, Non-ideal phenomena in osmotic flow through selective membranes, J. Membr. Sci. 12 (1982) 87-99.

[47] A.P. Straub, C.O. Osuji, T.Y. Cath, M. Elimelech, Selectivity and mass transfer limitations in pressure-retarded osmosis at high concentrations and increased operating pressures, Environ. Sci. Technol. 49 (2015) 12551-12559.

[48] G.T. Gray, J.R. McCutcheon, M. Elimelech, Internal concentration polarization in forward osmosis: role of membrane orientation, Desalination 197 (2006) 1-8.

[49] A. Achilli, T.Y. Cath, A.E. Childress, Selection of inorganic-based draw solutions for forward osmosis applications, J. Membr. Sci. 364 (2010) 233-241.

[50] Y. Marcus, Concentration dependence of ionic hydration numbers, J. Phys. Chem. B 118 (2014) 10471-10476.

[51] V.N. Afanas' ev, Solvation of electrolytes and nonelectrolytes in aqueous solutions, J. Phys. Chem. B 115 (2011) 6541-6563.

[52] J. Wang, D.S. Dlamini, A.K. Mishra, M.T.M. Pendergast, M.C.Y. Wong, B.B. Mamba, V. Freger, A.R.D. Verliefde, E.M.V. Hoek, A critical review of transport through osmotic membranes, J. Membr. Sci. 454 (2014) 516-537.

[53] S. Bason, Y. Oren, V. Freger, Ion transport in the polyamide layer of RO membranes: composite membranes and free-standing films, J. Membr. Sci. 367 (2011) 119-126.

[54] T.K. Sherwood, P.L.T. Brian, R.E. Fisher, Desalination by reverse osmosis, Ind. Eng. Chem. Fundm. 6 (1967) 2-12.
[55] D.R. Paul, Reformulation of the solution-diffusion theory of reverse osmosis, J. Membr. Sci. 241 (2004) 371-386.

[56] Q. She, X. Jin, C.Y. Tang, Osmotic power production from salinity gradient resource by pressure retarded osmosis: effects of operating conditions and reverse solute diffusion, J. Membr. Sci. 401 (2012) 262-273.

[57] J.S. Yong, W.A. Phillip, M. Elimelech, Coupled reverse draw solute permeation and water flux in forward osmosis with neutral draw solutes, J. Membr. Sci. 392 (2012) 9-17.

[58] A. Ghermandi, R. Messalem, Solar-driven desalination with reverse osmosis: the state of the art, Desalin. Water Treat. 7 (2009) 285-296.

[59] B. Peñate, L. García-Rodríguez, Current trends and future prospects in the design of seawater reverse osmosis desalination technology, Desalination 284 (2012) 1-8.

[60] M. Thomson, D. Infield, A photovoltaic-powered seawater reverse-osmosis system without batteries, Desalination 153 (2003) 1-8.

[61] T.V. Bartholomew, L. Mey, J.T. Arena, N.S. Siefert, M.S. Mauter, Osmotically assisted reverse osmosis for high salinity brine treatment, Desalination 421 (2017) 3-11.

[62] N.Y. Yip, M. Elimelech, Performance limiting effects in power generation from salinity gradients by pressure retarded osmosis, Environ. Sci. Technol. 45 (2011) 10273-10282.

[63] A. Tiraferri, N.Y. Yip, W.A. Phillip, J.D. Schiffman, M. Elimelech, Relating performance of thin-film composite forward osmosis membranes to support layer formation and structure, J. Membr. Sci. 367 (2011) 340-352.

[64] D.L. Shaffer, J.R. Werber, H. Jaramillo, S. Lin, M. Elimelech, Forward osmosis: where are we now? Desalination 356 (2015) 271-284.

[65] S. Zhao, L. Zou, C.Y. Tang, D. Mulcahy, Recent developments in forward osmosis: opportunities and challenges, J. Membr. Sci. 396 (2012) 1-21.

[66] C. Klaysom, T.Y. Cath, T. Depuydt, I.F.J. Vankelecom, Forward and pressure retarded osmosis: potential solutions for global challenges in energy and water supply, Chem. Soc. Rev. 42 (2013) 6959-6989.

[67] Z. Wang, A. Deshmukh, Y. Du, M. Elimelech, Minimal and zero liquid discharge with reverse osmosis, Water Res. 170 (2020) 115317. 